NBER WORKING PAPER SERIES

\title{
MORTALITY INEQUALITY IN CANADA AND THE U.S.: DIVERGENT OR CONVERGENT TRENDS?
}

\author{
Michael Baker \\ Janet Currie \\ Hannes Schwandt \\ Working Paper 23514 \\ http://www.nber.org/papers/w23514 \\ NATIONAL BUREAU OF ECONOMIC RESEARCH \\ 1050 Massachusetts Avenue \\ Cambridge, MA 02138 \\ June 2017, Revised November 2018
}

The authors thank Boriana Miloucheva, Jiaqi Zou, Matthew Schwartzman, and Carolyn Tsao for exceptional research assistance and David Card, Phil Oreopoulos, two referees and participants at the Oct. 2016 authors conference for helpful comments. Financial support from the Canada Research Chairs program and the Princeton Center for Translational Research on Aging (2P30AG024928) is gratefully acknowledged. Much of the analysis for this paper was conducted at the Toronto Region Statistics Canada Research Data Centre, which is part of the Canadian Research Data Centre Network (CRDCN). The services and activities provided by the CRDCN are made possible by the financial or in-kind support of the SSHRC, the CIHR, the CFI, Statistics Canada and participating universities whose support is gratefully acknowledged. The views expressed in this paper do not necessarily represent the CRDCN's, its partners, or the National Bureau of Economic Research.

NBER working papers are circulated for discussion and comment purposes. They have not been peer-reviewed or been subject to the review by the NBER Board of Directors that accompanies official NBER publications.

(C) 2017 by Michael Baker, Janet Currie, and Hannes Schwandt. All rights reserved. Short sections of text, not to exceed two paragraphs, may be quoted without explicit permission provided that full credit, including $(\odot$ notice, is given to the source. 
Mortality Inequality in Canada and the U.S.: Divergent or Convergent Trends?

Michael Baker, Janet Currie, and Hannes Schwandt

NBER Working Paper No. 23514

June 2017, Revised November 2018

JEL No. I14

\section{ABSTRACT}

Mortality is a crucial indicator of wellbeing and recent mortality trends have been a subject of public debate in many Western countries. This paper compares mortality inequality in Canada and the U.S. over the period 1990/91 through 2010/11. In Canada, mortality inequality remained constant among the youngest, but increased for men over 24 and for women over 14. In contrast, in the U.S. mortality inequality fell for children and youth, while at older ages it either modestly decreased or held steady. By 2010/11 the initially higher U.S. rates of infant and child mortality had almost converged to their Canadian counterparts.

Michael Baker

Department of Economics

University of Toronto

150 St. George Street

Toronto, ON M5S 3G7

Canada

and NBER

baker@chass.utoronto.ca

Janet Currie

Department of Economics

Center for Health and Wellbeing

185A Julis Romo Rabinowitz Building

Princeton University

Princeton, NJ 08544

and NBER

jcurrie@princeton.edu
Hannes Schwandt

SIEPR

366 Galvez Street Stanford

and CEPR

schwandt@northwestern.edu 


\section{Introduction}

Mortality rates are a closely watched indicator of the well being of a population. In the U.S., a strong overall decline in mortality rates since 1990 prompted studies of the extent to which the gains have, or have not, been equally shared (e.g. Cutler et al. 2011; Chetty et al. 2016; NRC 2015; Case and Deaton 2015). Most recently, overall U.S. life expectancy actually fell (Xu et al. 2016), an extraordinary development which would seem to bear out earlier studies warning that some U.S. groups were not benefitting from improvements in longevity to the same extent as others (Olshansky et al. 2012; Wang et al. 2013; Murray et al. 2006).

While economists and demographers have made great strides documenting these trends, little progress has been made in understanding the social factors underlying them. Aizer and Currie (2014) and Currie and Schwandt (2016a,b) show that inequality in mortality declined sharply for infants, children, and young adults between 1990 and 2010, while rising among older white adults. They argue that social investments in children, and in particular the extension of public health insurance to millions of low income children beginning in the late 1980s, may be responsible for at least some of the improvements in the health status of poor children in the U.S.

Chetty et al. (2016) focus on older adults, and show that some characteristics of local areas (commuting zones) are associated with better outcomes for the poor. Specifically, they find that low income people "live longest in affluent cities with more educated people and higher local government expenditures..." and that declines in life expectancy are also concentrated in certain areas such as Nevada, Appalachia, and southern Ohio. These results suggest there may be characteristics of particular areas that affect everyone living in that location.

This paper contributes to this literature by examining inequality in mortality in Canada, and comparing it to the U.S. In order to facilitate comparison, we treat Canadian and U.S. 
mortality in a parallel way. We first rank areas by indicators of socioeconomic status and then group the areas into ventiles of the population (i.e. each group represents five percent of the national population). We then examine the relationship between these rankings and mortality in 1990/1991, 2000/2001, and 2010/2011 (U.S./Canada). While many studies in the literature on mortality trends examine life expectancy, we focus exclusively on age-specific mortality rates. Life expectancy collapses all the mortality rates for different ages into a single number. In a context with changing mortality rates, this number is not informative about the expected longevity of any past, current, or future cohorts. To our knowledge, this is the first time that Canadian mortality data has been examined in this way.

In Canada, we find strong overall reductions in mortality levels. For children and youths, these reductions are similar in more advantaged and less advantaged areas, implying little change in inequality in mortality among the young. However, among men over 24 and women over 14, improvements in mortality are concentrated in more advantaged areas, so that there were large increases in inequality of mortality in Canada.

The U.S. started with higher levels of mortality in 1990, and mortality rates remained above Canadian levels at all ages two decades later despite significant declines. However, mortality fell sharply for infants, children, and youths in the U.S. and the gains were greatest in the most disadvantaged areas implying a considerable reduction in inequality in mortality among the young. In fact, U.S. infant and child mortality rates had almost converged to lower Canadian rates by 2010. This improvement may reflect the extension of public health insurance to U.S. pregnant women and children that began in the late 1980s. Since Canada already had universal public health insurance, gains in the U.S. might have been expected to close the gap between the two countries at young ages.

Finally, we ask what causes of death drive these developments. The leading causes of death differ by age. Accidents are a leading cause for younger age groups, while heart 
disease and cancer become important at older ages. Combined with the results regarding inequality in mortality, our results suggest that increases in health insurance among younger Americans in disadvantaged areas may have helped them to gain access to trauma care, reducing inequality in mortality from injuries across areas. At older ages, improvements in treatment for heart disease and cancer had a greater impact in richer areas, increasing inequality in mortality across areas. Among the middle aged, accidental deaths surged in the U.S. and failed to decline in Canada reflecting the impact of the opioid epidemic on accidental drug poisonings. In the poorest areas, this increase was large enough to wipe out gains in mortality from other causes, so that inequality in mortality between high SES and low SES areas increased.

\section{Background and Conceptual Issues}

According to a recent National Academy report there are three ways to measure inequality in mortality: "One looks at differences in the mortality of populations of U.S. counties in relation to county-level economic measures. Another looks at mortality by educational attainment. A third approach looks at mortality by career earnings" (NRC, 2015).

This third approach may be what most people have in mind when they think of inequality in mortality. If we had a measure of lifetime income for each deceased person, as well as for each member of the population, then it would be a simple matter to construct mortality rates for people with different lifetime income levels. For example, at each age and point in time, we could rank people in the population by their lifetime income, group them into 20 ventiles from richest to poorest and estimate a model of the form:

$$
\text { Mortality }_{a, v, t}=\alpha+\beta \operatorname{Rank}_{a, v, t}+\epsilon_{a, v, t}
$$

where Mortality is the mortality rate for age $a$, ventile $v$, and year $t$, and rank is the rank 
of the ventile. The slope $\beta$ would represent the gradient between ventile rank and mortality rates. A value of zero would indicate that there was no relationship between mortality rates and this measure of socioeconomic status, while higher levels of $\beta$ would correspond to higher levels of inequality in mortality.

However, Canadian and U.S. mortality data do not have information about the decedent's income or education. U.S. mortality data does have information about occupation for adults, but this data is not available for children, is often missing, especially for the elderly, and can be a very crude approximation to an individual's lifetime socioeconomic status. Following the pathbreaking study of Kitagawa and Hauser (1973) merging Census and mortality data, several studies examine mortality by income levels using social security earnings records or tax records linked to death records (NRC, 2015; Pappas et al., 1993; Waldron, 2007, 2013; Bosworth and Burke, 2014; Pijoan-Mas and Ríos-Rull, 2014; Chetty et al., 2016; Duggan et al., 2008; Duleep, 1989). In Canada, a similar approach has been followed, linking Census data to death records (Mustard et al., 1997, 2013) or linking data from the Canada Pension Plan data to death records (Wolfson et al., 1993; Milligan and Schirle, 2018).

These approaches have the great strength of having actual earnings and deaths for individuals, but they also have some weaknesses: an individual's social security earnings are only a partial record of lifetime income, particularly for women, and for younger cohorts of adults, and are not available for children. Moreover, there are many deaths that cannot be linked to an earnings record so that the samples are selected to be those who were healthy enough to work and had reasonably strong labor force attachment, a fraction of the population that may change over time. These administrative data also generally lack information about characteristics such as education.

Other U.S. studies use longitudinal data bases such as the Health and Retirement Study (NRC, 2015; Bosworth and Burke, 2014; Pijoan-Mas and Ríos-Rull, 2014) or the Survey of Income and Program Participation (Cristia et al. (2007); Attanasio and Hoynes (2000); 
Bosworth et al. (2016)). Measures of socioeconomic status available in these studies are much richer than those typically available in administrative data, but the sample is relatively small, and may have limited coverage. For example, the HRS survey covers only people 55 and older.

Another conceptual issue is that low income could be caused by ill health rather than the reverse (Smith, 1999, 2005, 2007). Hence, instead of lifetime income, a preferred measure might be someone's potential lifetime income. Education is often viewed as an indicator of potential, and many studies divide the adult population by levels of education rather than income (Pappas et al., 1993; Elo and Preston, 1996; Preston and Elo, 1995; Olshansky et al., 2012; Meara et al., 2008; Cutler et al., 2011; Montez and Zajacova, 2013; Montez and Berkman, 2014). Once again, this measure is absent from vital statistics mortality data, and is not available for children.

Still another issue is that the share of the population with high school or college has increased dramatically over time (Dowd and Hamoudi, 2014; Hendi, 2015; Bound et al., 2014; Goldring et al., 2016). If, for example, those who would have been expected to have less than a high school education in 1990 have moved into higher education categories by 2010, then it would not be surprising if the remaining high school drop outs proved to be less healthy in 2010 than high school dropouts were in 1990. That is, one could see divergence between the health of educational groups, even if there was no divergence in the health of individuals, simply because some relatively healthy individuals switched from one group to another group. This issue is not insurmountable but does require grouping education levels such that one is comparing the same fractions of the population (i.e. the bottom and top quartiles of the population by education level) over time. Since education is quite "lumpy", it may be difficult to maintain groups of approximately equal size over time.

Finally, one can pursue the strategy we use here, and examine inequality in mortality by geographical areas. A key advantage of this approach is that geography is available for all 
deaths, including those of children and those of people with weak labor force attachment. Hence, we can examine all deaths for all age groups.

However, analyses of mortality across geographical areas can be complicated by selective migration. For example, the healthiest people in a declining area may migrate to a place with more jobs. Some previous studies have focused on mortality trends within small areas such as individual counties (for example, Kulkarni et al. 2011; Wang et al. 2013; Murray et al. 2006). Just as in studies using educational groups, these studies could suggest widening mortality gaps between areas even if there was no change in any individual's probability of mortality.

Singh and Siahpush (2006) divide U.S. counties based on a socioeconomic index for the population in 1980 and follow these same county groups up to 2000, in order to avoid these biases. We follow a similar strategy here, using county areas for the analysis of the U.S. data, and Census Division areas for the analysis of the Canadian data. ${ }^{2}$ While the focus on groups of counties mitigates the concern about migration into and out of individual counties, there may still be net migration from county groups. That is, the poorest group of counties could represent a changing share of the population over time. Currie and Schwandt (2016a,b) address this concern by reordering counties in each Census year and then re-grouping counties so that they are always following county groups that represent a fixed share (e.g. 5 percent) of the population. They show that in the U.S., the results are not affected by this re-ordering, suggesting that the ranking of counties by poverty rates is stable over time and that there have not been large population shifts away from the poorest counties. In what follows, we focus on areas ranked in 2001 and use a fixed ranking over the three Census years we consider. ${ }^{3}$

Inequality in mortality by geographic area is clearly related but not identical to inequality

\footnotetext{
${ }^{2}$ Census Divisions are a middle geographic area between the province and municipality. In many parts of the country they correspond to counties. In provinces without county subdivisions they are defined in consultation with the province as municipalities joined together for planning and shared services.

${ }^{3}$ Some prior Canadian studies have looked at inequality in mortality at the provincial or census metropolitan area level including Statistics-Canada (1999); Ross et al. (2000); Auger et al. (2012); Tjepkema et al. (2013).
} 
in mortality by individual lifetime income or education. To see how they are related, consider the following example. Suppose that we divide a country into twenty areas, from richest to poorest and that these areas do not have to be made up of contiguous subunits -we are just trying to group smaller geographic areas (such as counties) such that the ones that are closest in terms of poverty rates or median income are in the same groups. In a world with perfect sorting, the poorest people would live in the poorest area and the richest people would live in the richest area. If we were to estimate equation (1) using geographic groups, and if there were no neighborhood effects or effects of concentrating poor and rich people in one place, then we would estimate exactly the same $\beta$ as we would have obtained by dividing the population into income groups because with perfect sorting the geographical groups and the income groups would be identical.

If on the other hand, we had perfect mixing across geographic areas and no neighborhood effects, then estimating (1) using geographic groups would yield a slope of zero. In practice, we know that there is neither perfect sorting nor perfect mixing. Average incomes vary considerably between areas but not by as much as they vary between individuals, which implies that if the extent of sorting were the only consideration, then estimates of (1) using geographic groups would be expected to yield a coefficient between zero and the $\beta$ obtained sorting by income groups.

However, sorting may not be the only consideration because of the type of neighborhood effects discussed by Chetty et al. (2016). Mortality rates could differ between rich areas and poor areas because of better quality medical care, lower violent crime rates, safer transportation, and lower pollution for example. The effects of all of these amenities would be to make the relationship between socioeconomic status and mortality steeper, since in practice richer people tend to live in neighborhoods better neighborhoods along these dimensions. At present, we have few studies that separate these kinds of true neighborhood effects from the effects of sorting. That is, we don't know if mortality rates are lower in some neighborhoods 
because healthier people have moved there, or because there really is something about the area that promotes or harms people's health sufficiently to cause differences in mortality. Moreover, arguably a county or a commuting zone is not really a neighborhood in the sense that there is considerable variation in amenities within these areas that is hard to capture statistically because measurements don't consistently exist at a smaller scale.

It is difficult to compare the gradients estimated for the U.S. in Currie and Schwandt (2016a,b) using sorting by geography to those in the literature based on sorting by income. The former are based on all deaths and the later are based on selected samples of deaths. However, if we focus, for example, on middle aged and older men where the selection effects may be less severe than for other demographic groups, the profiles estimated using sorting by geography are generally flatter than the corresponding profiles estimated using sorting by income. A possible interpretation of this result is that the mixing of people with different income levels within geographic areas results in a lower $\beta$.

Whether inequality across geography is mainly due to sorting or neighborhood effects is important in determining appropriate policy responses. If differences in mortality between areas mainly reflect sorting, then the most effective policies are likely to be those targeted to needy individuals within areas rather than to neighborhoods per se. However, we will not be able to definitively answer this question here.

\section{Data and Methods}

\subsection{Canadian Data}

Canadian death counts come from Canadian Vital Statistics: Deaths Database (CVS:D). Vital statistics are collected in Canada at the provincial or territorial level and transferred to Statistics Canada. The registration of death is a legal requirement in all provinces and 
territories and the report of deaths is virtually complete. ${ }^{4}$ Counts of population come from the "short form" files of the censuses of population for 1991, 2001 and 2011. The short form records a set of basic characteristics of the Canadian population. Estimated mortality rates based on these two courses are related to economic and demographic characteristics of the decedent's usual place of residence from the 1991 and 2001 "long form" censuses and from the 2011 National Household Survey. The long form is a supplementary Census questionnaire administered to 20 percent of the population.

Historically, completion of both the short and the long Census forms has been mandatory, but for the 2011 Census, the federal government of the day replaced the mandatory long form census with the voluntary National Household Survey (NHS) which was distributed to onethird of households. The response rate to the survey was about 69 percent, compared to response rates above 90 percent for the previous long form censuses. As a result, the 2011 data have greater sampling error, particularly at small areas of geography. To minimize the impact of these issues with the NHS we use economic and demographic characteristics from the 2001 long form census for every year in our main results.

We draw counts of deaths for the years 1990-1992, 2000-2002 and 2010-2012 and construct 3-year mortality rates. These data are organized into ten-year age groups, with the exception of the groupings of ages 0-4 and 75+. We calculate these 3-year death rates at the level of Census Division (CD) groups. CDs are secondary geographical areas, below the provinces and territories but larger than the tertiary census sub-divisions (e.g., municipalities). We restrict our sample to the provinces, thereby omitting the Yukon, the Northwest Territories, and Nunavut. In five of 10 provinces, CDs correspond to county divisions. ${ }^{5}$

We relate 3-year death rates for a given ten-year age group at the CD level to a measure of educational attainment and to an estimate of the level of "poverty" in a CD. Our measure of educational attainment is the proportion of the adult population (age 19 and above) who

\footnotetext{
${ }^{4}$ The deaths of non residents of Canada are registered at the provincial level but excluded from the CVS:D.

${ }^{5}$ They do not correspond primarily in provinces that do not have a county organization.
} 
did not complete a high school diploma.

Unlike the US, Canada does not have an official poverty measure. However, the LowIncome Cut-offs (LICOs) produced by Statistics Canada are often treated as though they were poverty measures, although Statistics Canada is emphatic that the LICO does not measure poverty. ${ }^{6}$ The LICO is based on the expenditures of Canadian families on food and shelter as measured in expenditure surveys. A family is judged to fall below the LICO if they spend over 20 percentage points more of their income than the average family on food and shelter. ${ }^{7}$ The proportion of income spent on food and shelter for the average family was last estimated in 1992, and since then LICO has been updated by adjusting the 1992 measure for price inflation. ${ }^{8}$

Like the US poverty measure, LICO income cutoffs vary by family size. However, in contrast to the US poverty measure, LICO cut-offs also vary by city size, with cities divided into five groups. These adjustments are intended to capture geographical variation in the price of food and shelter. To account for this difference in the Canadian and US measures, we construct a "fixed-cutoff LICO" by calculating the low-income rate using income cut-offs that vary only by family size not city size. Specifically, we use the 2001 LICO for "small urban regions", which are urban areas of less than 30,000 people, and apply them to all CDs. These income cut-offs are approximately equal to the cutoffs for the US poverty measure in 2001, at current exchange rates. In the Appendix we compare mortality profiles by our fixed-cutoff LICO to the profiles by the "standard" LICO which incorporates the variation by city size. For some age groups these two orderings provide contrasting results, which can be accounted for by their different placement of Montreal, Toronto and Vancouver within the

\footnotetext{
${ }^{6}$ See, for example the Chief Statistician's statement in 1997, Ivan Fellegi "On poverty and low income" http://www.statcan.gc.ca/pub/13f0027x/13f0027x1999001-eng.htm (accessed on March 20, 2017).

${ }^{7}$ For more detail see the Statistics Canada publication "Low income cut-offs for 2008 and low income measures for 2007" http://www.statcan.gc.ca/pub/75f0002m/2009002/s2-eng.htm (accessed on March 21, 2017).

${ }^{8}$ Note that this is not unlike the U.S. poverty measure that is based on an inflation adjusted minimal diet from 1963 and family expenditures shares from the 1950s.
} 
distribution of poverty. ${ }^{9}$

\subsection{Ranking Canadian CDs by socioeconomic indicators}

In this study, we explore alternative rankings of CDs by the percent of the population with less than 12 years of education and using the fixed-cutoff LICO that we described above. Appendix Figure A.2 shows the rankings of CDs by the share with less than 12 years of education in 1991, 2001, and 2011. This share ranges from about $15 \%$ in the most educated CDs to around $60 \%$ in the least educated. If both the shares and the rankings had remained exactly the same, the lines would lie on top of each other. The fact that the blue triangles (for 1991) lie above the dashed line, while the green dots (for 2011) lie below it indicates that the share of the population with less than 12 years of education has fallen over time. However, for our purposes, the important point is that the lines are generally parallel and strictly increasing, suggesting that the ranking of CDs is relatively constant.

Figure A.3 shows a similar comparison for the fixed-cutoff LICO. Most of the CDs are close to the dashed 45 degree line, indicating that the ranking remained fairly stable. Since LICO is not a measure of poverty per se, but a measure of relative income deprivation, perhaps this result is not surprising. For our purposes, it means that we can use CD rankings in 2001 without doing violence to the data in the other years. Recall this allows us to avoid the concerns over the response rates in the 2011 NHS.

\footnotetext{
${ }^{9}$ In the course of this research, we discovered that the largest Canadian cities tend to have high shares of "low income" people according to LICO primarily because Statistics Canada defines the level of income that is necessary for food and shelter to be higher in these locations. Figure A.1 shows how the rankings by education and alternative poverty measures compare. The high school drop out rate in 2001 is on the $\mathrm{x}$ axis, while the $y$-axis shows the 2001 LICO measures. The rankings by education and fixed-cutoff LICO are positively correlated. In other words, sorting CDs by education or by the fixed-income LICO results in similar rankings. But there is actually a slightly negative relationship between Canada's official LICO and the share of high school dropouts because of the treatment of larger CDs. Mortality is lower in large Canadian cities, but because Statistics Canada considers the share low income to be higher in large cities, there is actually an overall negative relationship between the share below LICO and mortality across CDs. There has been a spirited debate in the economics literature recently about how amentities in larger cities should be valued and set against their often higher costs (Moretti (2013); Diamond (2016)). Further discussion of this issue appears in the Appendix section A.
} 


\subsection{U.S. Data}

In the U.S. we use data from Vital Statistics Mortality and from the Census (in 1990 and 2000) and from the American Community Survey (ACS) in 2010 since the ACS replaced the long form of the Census. Population estimates for 1990 are based on NCHS bridged population estimates (NCHS, 2004), to account for reporting problems in the 1990 Census, which affected population counts for infants in that year. Indicators of socioeconomic status, including the share of the population that had less than 12 years of education and the poverty rate, are taken from the U.S. Census (in 1990 and 2000) and from the ACS in 2010.

\subsection{Method}

Following Currie and Schwandt (2016a,b), we first rank Canadian CDs (and U.S. counties) by an indicator of socioeconomic status. ${ }^{10}$ We then group CDs (counties) into 20 bins, each representing about 5\% of the Canadian (U.S.) population and calculate mortality rates for each age and gender group. ${ }^{11}$

Grouping CDs (counties) into equal shares of the population helps to address the problem of measurement error in mortality rates for small areas (small cell sizes), in particular when analyzing age ranges with low mortality. We focus on 3-year mortality rates for the same reason. In the Canadian data we calculate the 3-year mortality rate in 1991 as the ratio of all deaths that occurred in a cohort between January 1, 1990, and December 31, 1992, divided

\footnotetext{
${ }^{10}$ In the U.S., the geographic distribution of the counties with the highest and lowest poverty rates remained fairly stable between 1990 and 2010, and whether we readjust county groups to account for population changes or instead follow fixed sets of poor and rich counties over time has little impact on the results.

${ }^{11}$ In order to smooth the size of the county groups in the U.S. we divide the five largest counties in our sample-Cook County, Illinois (which includes the city of Chicago), Los Angeles County, California, Riverside County, California, Harris County, Texas (including Houston), and Maricopa County (including Phoenix), Arizona into three smaller groups, each of identical size and with the identical mortality rate. Dividing counties into groups that represent equal fractions of the population is not an exact procedure because counties at the margin will overlap the bins, making one group too large and the next group too small. In practice, however, this variation in county group size is relatively small. Given data constraints, we were not able to similarly divide the large cities of Toronto, Vancouver, and Montreal into smaller units. See the Appendix for further discussion of this issue.
} 
by the 1991 Census population count. We use the decedent's CD of residence, rather than the $\mathrm{CD}$ where the death occurred. In the U.S. data we calculate the 3-year mortality rate in 1990 as the ratio of all deaths that occurred in a cohort between April 1, 1990, and March 31, 1993, divided by the 1990 Census population count. We again use the decedent's county of residence, rather than the county where the death occurred. ${ }^{12}$

\subsection{Mortality by age in Canada and the U.S.}

Figure 1 shows mortality rates for every age and both genders in Canada and the U.S. in 2009-2011. One can clearly see the "hockey-stick" pattern in log mortality by age: Mortality rates are high for infants and fall precipitously in early childhood. They start to rise again in the teenage years and continue rising. Mortality rates do not begin to exceed those in very early childhood until after age 50. The large gender differences are also remarkable: Death rates for males exceed those for females at every age. The gap between males and females is especially pronounced during the teen years and in young adulthood and starts to narrow starting around age 35 or 40 . Although we will not present detailed analyses by cause of death, it is worth bearing in mind that injuries (both intentional and unintentional) are the primary cause of death among teens and young adults by a wide margin, as shown in Tables A1 and A2. Males are much more likely to die of injuries than females, and a large part of the gap in death rates between the U.S. and Canada appears to be due to higher death rates from injuries (both intentional and unintentional).

A third fact that is especially salient for our study is that the gender-specific mortality rates are higher in the U.S. than in Canada at all ages. That is, Canadian men are less likely than U.S. men to die at all ages, and the same is true when comparing women across countries. Canadian women have the lowest mortality rates of the four demographic groups

\footnotetext{
${ }^{12}$ This slight difference in the calculation of the death rates between the two countries is necessitated by the fact that the Canadian vital statistics for the years 2013 and later are not yet available for research, and so we cannot use the method for the US data for the Canadian death rates in 2011.
} 
we consider, followed by U.S. women. At some ages, Canadian men have mortality rates similar to U.S. women, but Canadian men have higher mortality than U.S. women in the teen and young adult age range, and again after age 50. It is important to keep these level differences in mind when examining trends in mortality. Because men and women have systematically different mortality rates, we analyze them separately below.

\section{Results}

\subsection{Trends in Inequality in Mortality in Canada by Education}

Figure 2 focuses on Canadian males, and shows the relationship between mortality and the share of the area population with less than a high school education, by age category in each Census year. There are 20 points in each figure for every Census year, each point corresponding to a group of CDs. The least educated areas are to the left of each graph, while the highest educated are to the right. To aid in interpretation, we have fitted straight lines through the 20 points for each Census year. The lines are usually upward sloping, because places with more high school dropouts tend to have higher mortality. In these diagrams and those that follow, lines that are lower and flatter are better. Lower lines correspond to lower mortality, while flatter lines correspond to less inequality in mortality.

The figures for ages 0-24 show overall reductions in mortality between 1991 and 2011 . The declines were slightly larger in areas with large numbers of high school dropouts, suggesting a small reduction in inequality in mortality over time. In contrast, there is a pronounced increase in inequality in mortality among those aged 25 and over in Canada. This increase can be seen in the graphs by the fact that the lines are steeper in 2011 than in 1991; that is, mortality fell by a greater amount in places with few dropouts. Indeed, among 3544 year old Canadian men, mortality appears to have shown no improvement at all in the areas with the most dropouts. In 1991, there was little relationship between the share of 
high school dropouts in an area and mortality among 30 to 44 year olds, but this share had become much more predictive of mortality by 2011 , largely because mortality fell in more educated areas. At older ages (age 50 and above) mortality decreased strongly for all education groups. But as in the middle aged groups, improvements were stronger in more educated areas, implying an increase in mortality inequality.

Figure 3 shows that these patterns are even more pronounced among females and appear at younger ages. Female mortality fell in the areas with the fewest dropouts for all ages, but showed little improvement in the areas with the most high school dropouts among 15-54 year old women and among women 75 and over. The result is that inequality in mortality between more and less educated areas generally increased for women over 15 years old.

\subsection{Trends in Inequality in Mortality by Fixed-Cutoff LICO}

The huge expansion of the natural resource extraction sector in Canada since 1990 means that in Canada, areas with low education are not necessarily those with low income. For example, Fort McMurray is one of the wealthiest areas in Canada but many of the jobs are blue collar and do not necessarily require high school or college education. ${ }^{13}$ Hence it is interesting to also rank CDs by the fixed cutoff LICO measure.

Figure 4 shows that male mortality has declined across the income distribution, and that for males less than 45, it declined more in places with larger shares of low income people, that is, in places towards the right hand part of each graph. For men 45 and older, it appears that mortality declined similarly in high income and low income areas. Therefore, in contrast to the ranking in Figure 2 by education, the ranking by fixed-cutoff LICO does not show a strong increase in the inequality of mortality over the period for older age groups.

The corresponding results for females in Figure 5 are more supportive of the inference in Figure 3. Here, just as in Figure 3, among women over 15, there were greater declines in

\footnotetext{
${ }^{13}$ See: http://globalnews.ca/news/370804/income-by-postal-code/, accessed April 12017.
} 
mortality in the places with the fewest low income people resulting in increases in inequality in mortality. This pattern is especially pronounced among women 15-24 and 35-44 years old.

Taken as a whole, these results show strong increases in inequality in mortality among Canadian adult women over 15. Among men, whether one observes increases in inequality in mortality or decreases across areas depends on how one ranks. Ranking by education suggests increases in inequality in mortality between 25 and 54, whereas ranking by poverty rates implies decreases in inequality in mortality at those ages. A possible explanation is that there are areas that have an increasing share of relatively low education men with high incomes, such as in the resource sector. If these sectors have high mortality, than they could generate the pattern we see for prime age men: That both places with high shares of high school dropouts and places with low poverty shares experienced slower than average declines in male mortality. These results may suggest that policies aimed at reducing inequality in mortality might work better if they are targeted to areas with less education rather than at areas with more low income people.

\subsection{Comparing trends in the U.S. and Canada}

Figures 6 and 7 compare mortality trends in the U.S. and Canada, ranking areas by their high school dropout rates (as in Figures 2 and 3). To avoid clutter, we do not plot the points for each area, but only show lines fitted through the points for each Census year. The thick and thin solid blue lines refer to U.S. rates in 2010 and 1990, respectively. The thick and thin dashed red lines show rates for Canada in 2011 and 1991.

We begin with the developments among male infants, children, and young adults up to age 24 as shown in the top three graphs of Figure 6. Just as in Figure 1, mortality levels are were generally higher in the U.S. than in Canada in 1990/1991, and the slope of the lines was steeper, indicating greater inequality in mortality in the U.S. than in Canada. This 
pattern changes considerably over the following two decades due to differential trends in both countries.

Between 1991 and 2011, male mortality rates in Canada decreased relatively uniformly across areas for children and youths less than 25 , as reflected by the parallel downward shifts of the dashed red lines which were also discussed above with reference to Figure 2 . In the U.S., on the other hand, mortality in the same age groups declined more strongly in areas with higher dropout rates, leading to a considerable flattening of the solid blue lines. Despite the steeper slope of the US lines in 1990/1991, the gradients are actually flatter in the U.S. than in Canada in 2010 for males 5 to 24. In the least educated areas, U.S. mortality rates converged to Canadian ones in these age groups by 2010/2011, while in more educated areas, Canada continued to enjoy lower mortality.

Turning to young adults and the middle aged, in Canada mortality improvements between age 25 and 45 are concentrated in more educated areas, with little or no improvement in the areas with the highest dropout rates, implying a considerable increase in inequality in mortality. In contrast, U.S. areas with high dropout rates experienced strong male mortality reductions, while mortality rates in areas with low dropout rates stagnated. As a result, there is strong evidence of an decrease in mortality in higher educated areas of Canada that was not shared by more educated areas of the U.S.

The opposing developments across the two countries imply that inequality in male mortality was actually lower in the U.S. than in Canada in 2010/11, even though the level of mortality remained higher in the U.S.

At ages 45 to 74 , there were strong reductions in male mortality in both countries that were relatively uniform across areas, with only small changes in inequality in male mortality, and mortality remained more unequally distributed in the U.S. than in Canada. Above age 75, there were large downward shifts in mortality; but in Canada these shifts were again largest in the most educated places, leading to a noticeable increase in inequality in mortality in old 
age.

Figure 7 shows striking differences in the evolution of female mortality in the U.S. and Canada between 1990/1991 and 2010/2011. Children less than 15 saw large reductions in mortality in both countries; however, in the U.S. these were concentrated in less educated areas, while in Canada, the shift was roughly parallel. For women 15 to 44, mortality in the U.S. stagnated entirely in the most educated places, while it fell only slightly in the least educated places. In other words, the reduction in U.S. female mortality inequality observed at young ages continued at middle ages, but the more notable pattern is that overall U.S. female mortality hardly improved at middle ages over the past two decades. Of course, compared to men, U.S. female mortality was already at low levels in 1990. However, the comparison with middle aged women in Canada shows that further improvements are feasible.

In Canada, female mortality among those 15 to 54 fell mainly in the most educated places, and hardly at all in the least educated places. These developments were strong enough that by 2010/11, inequality in mortality was actually lower in the U.S. than in Canada for 15 to 34 year olds, and quite similar for 35 to 54 year olds. This convergence reflects reductions in inequality in mortality in the U.S. and increases in Canada. Among women 45 and older, inequality in mortality increased slightly in the U.S., and more strongly in Canada.

Figures A.8 and A.9 show similar comparisons of inequality in mortality trends in Canada and the U.S., but instead of the high school dropout rate we rank areas using the fixed-cutoff LICOs (Canada) and poverty rates (U.S.). In keeping with the results for fixed income LICO discussed earlier, there is little evidence of an increase in inequality across areas in Canada when they are ranked by this measure for males. In the U.S., the results are very similar using either poverty or the high school drop out rate to rank areas. Either method shows pronounced reductions in mortality in the most disadvantaged (least educated or poorest) areas at young ages, with the result that inequality in mortality fell for men up to age 44 . At older ages, the shifts in both Canada and the U.S. are roughly parallel, with the exception of 
age 75 plus, where once again, we see that in Canada reductions in mortality were greater in areas with less poverty.

Summing up, the comparison of mortality trends in Canada and the U.S. yields three main findings. First, in terms of levels, both countries have experienced large mortality improvements, with the U.S. starting at higher mortality levels in 1990 and remaining above Canada in 2010. Second, in terms of mortality inequality, the U.S. experienced a strong decrease in mortality inequality among male infants, children, and middle-aged adults, while inequality tended to increase among Canadian adult males. For females age 15 or older, inequality in mortality fell slightly in the U.S. and increased in Canada, but the most striking finding was the very modest improvements in mortality for women relative to men. Third, inequality in mortality increased in both countries at older ages, but only slightly in the U.S. compared to Canada. Overall then, Canadians experienced stable or increasing inequality in mortality while the U.S. saw decreases in inequality in mortality for some groups and comparatively small increases in inequality in mortality among others.

\subsection{Trends by Causes of Death in the U.S. and Canada}

Which causes of death are driving the mortality reductions that we observe in Canada and the U.S.? Appendix Tables A.1 and A.2 show the five leading causes of death for different age groups in Canada and the U.S. in 2011, as well as their growth rates over the past two decades. Among infants, children, and adolescents, the leading cause of death in 2011 is accidents (unintentional injuries), and the rate of fatal accidents is about 1.5 times larger in the U.S. than in Canada. There were significant improvements in both countries, with mortality reductions of about 50 to $60 \%$. Deaths due to assaults show a similar pattern, with both higher U.S. rates and stronger improvements in the U.S. than in Canada. However, assaults play a quantitatively less important role than accidents.

In young adulthood and middle age up to age 64, accidents remain a leading cause of 
death and they become an even more relevant source of cross-country disparity, with U.S. rates amounting to 2 to 2.5 times the Canadian rates. Moreover, there has been less improvement in accidental deaths over the past two decades in these age groups than at younger ages. In fact, in the U.S. the rate of fatal accidents in middle age increased strongly, by up to $80 \%$. This increase is mainly due to an exorbitant surge in deaths due to accidental drug poisonings (which are broken out separately in the tables). In the U.S. this death rate increased by $300 \%$ to $1,100 \%$ depending on the age and gender group, a development that was driven mainly by the opioid epidemic. Canada experienced milder but nevertheless singnificant increases in accidental drug poisonings, with increases ranging from $60 \%$ and $220 \%$. Another cause of death that has increased somewhat, in particular in the U.S., is suicide. But intentional selfharm is often difficult to distinguish from accidental drug poisioning, so both increases might represent the same underlying phenomenon. Overall, these negative developments in middle age are balanced by strong improvments that occurred with respect to cancer and heart disease deaths.

At age 65 and above, mortality in both countries has strongly declined for all leading causes, with the exception of female deaths due to chronic lower respiratory diseases. This cause is driven by smoking and increases in this subgroup could reflect the rising rates of female tobacco addiction that occured in these cohorts (see Currie and Schwandt (2016b) for a more detailed discussion). Smoking has strongly declined in more recent cohorts, suggesting that the increases in this cause of death might be reversed in future.

To sum up, there have been strong improvements in most of the leading causes of death across all ages. At younger ages, reductions in mortality due to accidents have been particularly relevant, while cancer and heart disease mortality played an important role at older ages. Increasing mortality rates due to accidental drug poisonings and suicides in the middle age groups slowed down the otherwise positive developments in those age groups. The results from the previous section suggest that the early life reductions in accidental deaths 
have been particularly pronounced in poorer and less educated areas in the U.S., while the improvments at older ages were more pronounced in more advantaged areas both in the U.S. and in Canada.

\subsection{Discussion}

While our analysis is mainly descriptive, it does provide evidence consistent with several hypotheses about the factors underlying different levels and trends in U.S. mortality rates for different ages. With respect to children, we observe that mortality rates fell in both countries, consistent with broad based technological changes (everything from new medical technologies to safer cars and carseats) that have improved health. However, trends in inequality in mortality are quite different in the two countries. In Canada, child mortality levels are fairly similar in high and low SES areas, whereas in the U.S., child mortality rates are higher in low SES areas, but have also shown more dramatic declines in these areas than in high SES areas.

This pattern is consistent with the idea that declines in inequality in child mortality in the U.S. may have been driven by the remarkable expansion of public health insurance for low income pregnant women and children that took place beginning the late 1980s and continuing through the early 2000s. As Currie et al. (2008) showed, these expansions resulted in large increases in eligibility: The fraction of children 0-3 eligible for Medicaid rose from approximately 20 to over 50 percent, and the fraction of children $13-17$ rose from 15 to over 40 percent by 2000 . At the margin, the available evidence suggests that providers who know that virtually all children are covered by insurance will be more likely to provide costly and potentially life saving services (Currie and Gruber, 1996a,b). ${ }^{14}$

Several recent papers follow the cohorts who became eligible for public health insurance

\footnotetext{
${ }^{14}$ Finkelstein (2007) shows that the introduction of Medicare (public health insurance for persons over 65 which was introduced in the U.S. 1965) had general equilibrium effects which resulted in increases in the availability of medical care. Card et al. (2009) shows that elderly people with life-threatening conditions gain access to life saving care when they turn 65 and gain access to Medicare.
} 
as a result of these Medicaid expansions. Brown et al. (2015) use U.S. Internal Revenue data from tax returns which allows them to examine disability and employment as well as income. Wherry and Meyer (2015) examine effects on mortality using Vital Statistics data while Wherry et al. (2015) look at hospitalizations and Emergency Room visits using hospital discharge data. All of these studies find positive long-term effects of having been eligible for health insurance coverage in childhood on young adult health, suggesting that the Medicaid expansions could potentially explain at least some of the declines in inequality in mortality among Americans up to about age 30 .

It seems unlikely, however, that expansions of public health insurance can explain the large reductions in mortality for adult males $35-44$ in the U.S. relative to Canada. In this age category, injuries (intentional and unintentional) are the leading cause of death. Improvements in automobile safety, for example, ought to have affected both Canadians and Americans, so they are not likely to explain the reduction in mortality in the U.S. relative to the Canada, or the large reduction in inequality in mortality in the U.S. among men in this age group. A decline in homicide may be partially responsible. Another possibility is that better trauma care is responsible for improved survival and that this has had a differential effect in the U.S. where low SES males are most likely to be the victim of both intentional and unintentional injuries.

For older males, we see reductions in mortality among males relative to females in both Canada and the U.S. This could reflect better care for conditions like heart disease (especially in the 65+ population where all Americans have health care). Again, since males were more likely to suffer from heart disease to begin with, improvements in medical care could have a differentially beneficial effect on them. Nevertheless, it is disturbing that middle aged women have seen such little improvement in mortality in either country, suggesting that more attention to the causes of the stalling in mortality decline in this group is warranted.

Finally, we observe strong decreases in mortality for prime aged adults in more educated 
areas of Canada that are not shared by similarly aged adults in more educated areas in the U.S. This is surprising, as certainly popular perception is that any medical innovations that save lives are made available in common practice more quickly in the U.S. than in Canada, particularly for the well off. An alternative explanation would be cross country differences in lifestyle in these age groups, which is an interesting hypothesis for future research.

All told, our results comparing Canada and the U.S. may be interpreted like a glass that is either half empty or half full. Canadians have systematically lower mortality in most age and SES categories. On the other hand, inequality in mortality is actually increasing among middle aged adults and older adults in Canada, suggesting little cause for complacency. Finally, the increase in deaths due to accidental poisonings, attributable largely to the opioid epidemic, is a disturbing development that merits further policy responses in both countries. 


\section{References}

Aizer, Anna and Janet Currie, "The intergenerational transmission of inequality: Maternal disadvantage and health at birth," Science, 2014, 344 (6186), 856-861.

Attanasio, Orazio P and Hilary Williamson Hoynes, "Differential mortality and wealth accumulation," Journal of Human Resources, 2000, pp. 1-29.

Auger, Nathalie, Denis Hamel, Jerome Martinez, and Nancy A. Ross, "Mitigating effect of immigration on the relation between income inequality and mortality: a prospective study of 2 million Canadians," Journal of Epidemiology and Community Health, 2012, 66 (6), e5.

Baker, Michael and Dwayne Benjamin, "The performance of immigrants in the Canadian labor market," Journal of Labor Economics, 1994, 12 (3), 369-405.

Bohnert, Nora, Jonathan Chagnon, Patrice Dion et al., Population projections for Canada (2013 to 2063), provinces and territories (2013 to 2038), Statistics Canada= Statistique Canada, 2015.

Bosworth, Barry and Kathleen Burke, "Differential mortality and retirement benefits in the Health and Retirement Study," 2014.

_, Gary Burtless, and Kan Zhang, "Later retirement, inequality in old age, and the growing gap in longevity between rich and poor," Economic Studies at Brookings, 2016, 87.

Bound, John, Arline T Geronimus, Javier M Rodriguez, and Timothy Waidmann, “The implications of differential trends in mortality for social security policy," 2014. Michigan Retirement Research Center Research Paper, 2014-314. 
Brown, David W, Amanda E Kowalski, and Ithai Z Lurie, "Medicaid as an Investment in Children: What is the Long-Term Impact on Tax Receipts?," 2015. National Bureau of Economic Research Working paper, 20835.

Card, David, Carlos Dobkin, and Nicole Maestas, “Does Medicare Save Lives?," The Quarterly Journal of Economics, 2009, 124 (2), 597-636.

Case, Anne and Angus Deaton, "Rising morbidity and mortality in midlife among white non-Hispanic Americans in the 21st century," Proceedings of the National Academy of Sciences, 2015, 112 (49), 15078-15083.

Chetty, Raj, Michael Stepner, Sarah Abraham, Shelby Lin, Benjamin Scuderi, Nicholas Turner, Augustin Bergeron, and David Cutler, "The association between income and life expectancy in the United States, 2001-2014," JAMA: Journal of the American Medical Association, 2016, 315 (16), 1750-1766.

Cristia, Julian P, Arlene Holen DeLeire, Howard Iams, Joseph Kile, Joyce Manchester, Noah Meyerson, John Sabelhaus, Hilary Waldron, Lina Walker et al., The empirical relationship between lifetime earnings and mortality, Congressional Budget Office, 2007.

Currie, Janet and Hannes Schwandt, "Inequality in mortality decreased among the young while increasing for older adults, 1990-2010," Science, 2016, 352 (6286), 708-712.

_ and _ , "Mortality inequality: The good news from a county-level approach," The Journal of Economic Perspectives, 2016, 30 (2), 29-52.

_ and Jonathan Gruber, "Health Insurance Eligibility, Utilization of Medical Care, and Child Health,” The Quarterly Journal of Economics, 1996, 111 (2), 431-466.

_ and _, "Saving Babies: The Efficacy and Cost of Recent Changes in the Medicaid Eligibility of Pregnant Women,” Journal of Political Economy, 1996, 104 (6), 1263-1296. 
_, Sandra Decker, and Wanchuan Lin, "Has public health insurance for older children reduced disparities in access to care and health outcomes?," Journal of Health Economics, 2008, 27 (6), 1567-1581.

Cutler, David M, Fabian Lange, Ellen Meara, Seth Richards-Shubik, and Christopher J Ruhm, "Rising educational gradients in mortality: The role of behavioral risk factors," Journal of Health Economics, 2011, 30 (6), 1174-1187.

Diamond, Rebecca, "The determinants and welfare implications of US workers' diverging location choices by skill: 1980-2000," The American Economic Review, 2016, 106 (3), 479-524.

Dowd, Jennifer B and Amar Hamoudi, "Is life expectancy really falling for groups of low socio-economic status? Lagged selection bias and artefactual trends in mortality.," International Journal of Epidemiology, 2014, 43 (4), 983-988.

Duggan, James E, Robert Gillingham, and John S Greenlees, "Mortality and lifetime income: evidence from US Social Security records," IMF Staff Papers, 2008, 55 (4), 566594.

Duleep, Harriet Orcutt, "Measuring socioeconomic mortality differentials over time," Demography, 1989, 26 (2), 345-351.

Elo, Irma T and Samuel H Preston, "Educational differentials in mortality: United States, 1979-1985," Social Science and Medicine, 1996, 42 (1), 47-57.

Finkelstein, Amy, "The aggregate effects of health insurance: Evidence from the introduction of Medicare," The Quarterly Journal of Economics, 2007, 122 (1), 1-37. 
Goldring, Thomas, Fabian Lange, and Seth Richards-Shubik, "Testing for changes in the SES-mortality gradient when the distribution of education changes too," Journal of Health Economics, 2016, 46, 120-130.

Green, David A and Christopher Worswick, "Immigrant earnings profiles in the presence of human capital investment: Measuring cohort and macro effects," Labour Economics, 2012, $19(2), 241-259$.

Hendi, Arun S, “Trends in US life expectancy gradients: the role of changing educational composition," International Journal of Epidemiology, 2015, 44 (3), 946-955.

Kitagawa, Evelyn M and Philip M Hauser, Differential Mortality in the United States: A Study in Socioeconomic Epidemiology, Harvard University Press, 1973.

\section{Kulkarni, Sandeep C, Alison Levin-Rector, Majid Ezzati, and Christopher JL Murray,} "Falling behind: Life expectancy in US counties from 2000 to 2007 in an international context," Population Health Metrics, 2011, 9 (1), 16.

McDonald, James Ted and Steven Kennedy, "Insights into the 'healthy immigrant effect': health status and health service use of immigrants to Canada,' Social Science \& Medicine, 2004, 59 (8), 1613-1627.

Meara, Ellen R, Seth Richards, and David M Cutler, “The gap gets bigger: Changes in mortality and life expectancy, by education, 1981-2000," Health Affairs, 2008, 27 (2), $350-360$.

Milligan, Kevin and Tammy Schirle, "The evolution of longevity: evidence from Canada," Technical Report, National Bureau of Economic Research 2018. 
Montez, Jennifer Karas and Anna Zajacova, "Explaining the widening education gap in mortality among US white women," Journal of Health and Social Behavior, 2013, 54 (2), 166-182.

_ and Lisa F Berkman, "Trends in the educational gradient of mortality among US adults aged 45 to 84 years: Bringing regional context into the explanation," American Journal of Public Health, 2014, 104 (1), e82-e90.

Moretti, Enrico, "Real wage inequality," American Economic Journal: Applied Economics, 2013, 5 (1), 65-103.

Murray, Christopher JL, Sandeep C Kulkarni, Catherine Michaud, Niels Tomijima, Maria T Bulzacchelli, Terrell J Iandiorio, and Majid Ezzati, "Eight Americas: Investigating mortality disparities across races, counties, and race-counties in the United States," PLoS Med, 2006, 3 (9), e260.

Mustard, Cameron A, Amber Bielecky, Jacob Etches, Russell Wilkins, Michael Tjepkema, Benjamin C Amick, Peter M Smith, and Kristan J Aronson, "Mortality following unemployment in Canada, 1991-2001,” BMC public health, 2013, 13 (1), 441.

_, Shelley Derksen, Jean-Marie Berthelot, Michael Wolfson, and Leslie L Roos, "Age-specific education and income gradients in morbidity and mortality in a Canadian province," Social Science \&amp; Medicine, 1997, 45 (3), 383-397.

NCHS, "Postcensal estimates of the resident population of the United States for July 1, 1990July 1, 1999, by year, county, single-year of age, bridged race, Hispanic origin, and sex.," 2004. - National Center for Health Statistics. Prepared under a collaborative arrangement with the U.S. Census Bureau.

Ng, Edward, “The healthy immigrant effect and mortality rates," Health Reports, 2011, 22 (4), C1. 
NRC, “The Growing Gap in Life Expectancy by Income: Implications for Federal Programs and Policy Responses,” 2015. National Research Council, Committee on the Long-Run Macroeconomic Effects of the Aging U.S. Population.

Olshansky, S Jay, Toni Antonucci, Lisa Berkman, Robert H Binstock, Axel BoerschSupan, John T Cacioppo, Bruce A Carnes, Laura L Carstensen, Linda P Fried, Dana P Goldman et al., "Differences in life expectancy due to race and educational differences are widening, and many may not catch up," Health Affairs, 2012, 31 (8), 18031813.

Pappas, Gregory, Susan Queen, Wilbur Hadden, and Gail Fisher, "The increasing disparity in mortality between socioeconomic groups in the United States, 1960 and 1986," New England Journal of Medicine, 1993, 329 (2), 103-109.

Pijoan-Mas, Josep and José-Víctor Ríos-Rull, "Heterogeneity in expected longevities," Demography, 2014, 51 (6), 2075-2102.

Preston, Samuel H and Irma T Elo, "Are educational differentials in adult mortality increasing in the United States?," Journal of Aging and Health, 1995, 7 (4), 476-496.

Ross, Nancy A, Michael C Wolfson, James R Dunn, Jean-Marie Berthelot, George A Kaplan, and John W Lynch, "Relation between income inequality and mortality in Canada and in the United States: cross sectional assessment using census data and vital statistics," BMJ, 2000, 320 (7239), 898-902.

Singh, Gopal K and Mohammad Siahpush, "Widening socioeconomic inequalities in US life expectancy, 1980-2000," International Journal of Epidemiology, 2006, 35 (4), 969979.

Smith, James, "Consequences and predictors of new health events," in "Analyses in the Economics of Aging," University of Chicago Press, 2005, pp. 213-240. 
Smith, James P, "Healthy Bodies and Thick Wallets: The Dual Relation Between Health and Economic Status,” The Journal of Economic Perspectives, 1999, 13 (2), 145-166.

_ , "The impact of socioeconomic status on health over the life-course," Journal of Human Resources, 2007, 42 (4), 739-764.

Statistics-Canada, "Income inequality and Mortality among working-age people in Canada and the US," Health Rep, 1999, 11 (3), 77-82.

Tjepkema, Michael, Russell Wilkins, and Andrea Long, Cause-specific mortality by income adequacy in Canada: A 16-year follow-up study, Statistics Canada, 2013.

Waldron, Hilary, "Trends in mortality differentials and life expectancy for male social security-covered workers, by socieoeconomic status," Social Security Bulletin, 2007, 67 (3), 1-28.

_, "Mortality Differentials by Lifetime Earnings Decile: Implications for Evaluations of Proposed Social Security Law Changes,” Social Security Bulletin, 2013, 73 (1), 1.

Wang, Haidong, Austin E Schumacher, Carly E Levitz, Ali H Mokdad, and Christopher JL Murray, "Left behind: Widening disparities for males and females in US county life expectancy, 1985-2010," Population Health Metrics, 2013, 11 (1), 8.

Wherry, Laura R and Bruce D Meyer, "Saving teens: using a policy discontinuity to estimate the effects of Medicaid eligibility," Journal of Human Resources, 2015, 51 (3), $556-588$.

_, Sarah Miller, Robert Kaestner, and Bruce D Meyer, "Childhood Medicaid coverage and later life health care utilization,” 2015. National Bureau of Economic Research Working paper, 20929. 
Wolfson, Michael, Geoff Rowe, Jane F Gentleman, and Monica Tomiak, "Career earnings and death: a longitudinal analysis of older Canadian men," Journal of Gerontology, 1993, 48 (4), S167-S179.

Xu, Jiaquaun, Sherry Murphy, Kenneth Kochanek, and Elizabeth Arias, "Mortality in the US, 2015,” Dec. 2016. Hyattsville MD, NCHS Data Brief No. 267. 


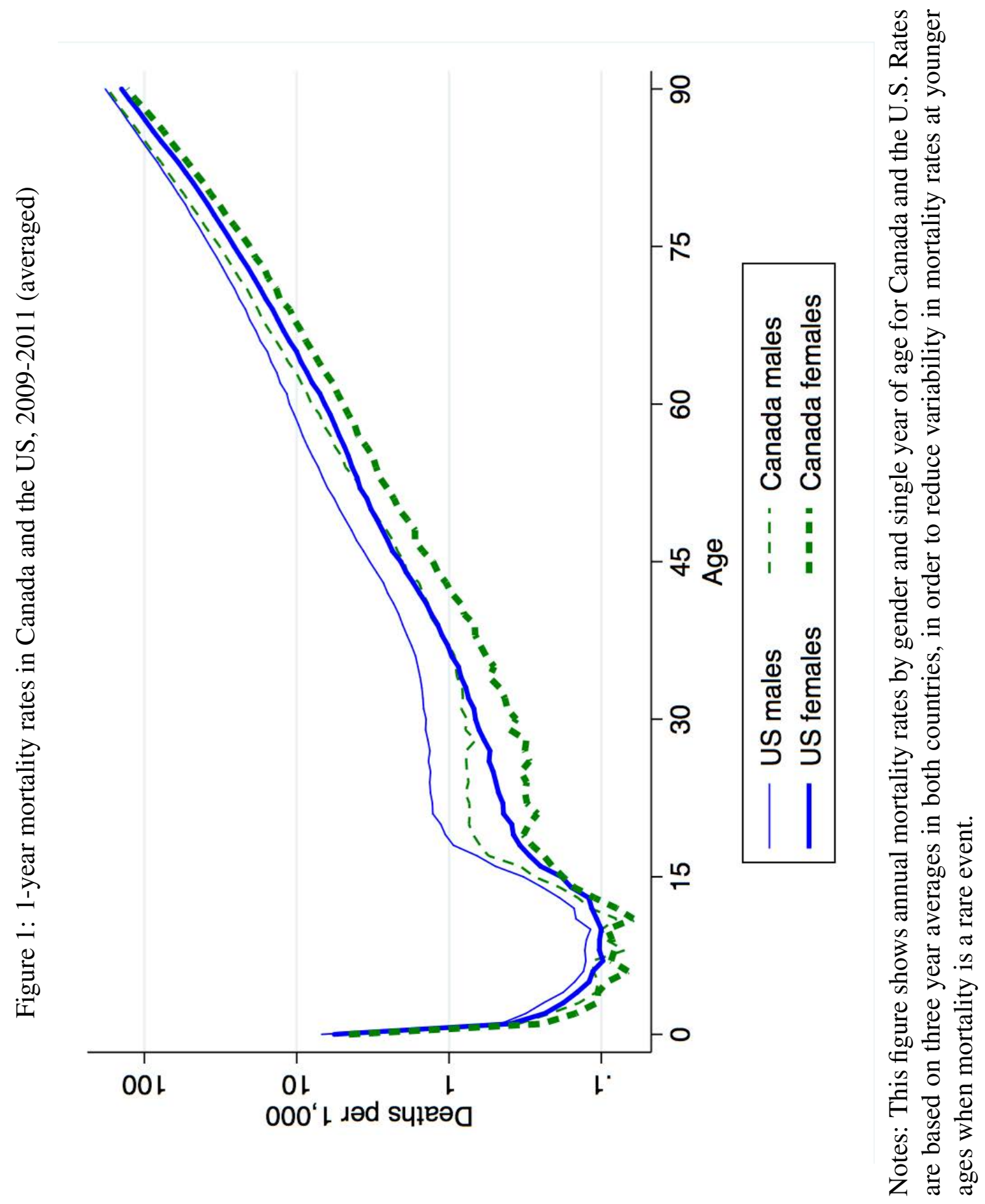




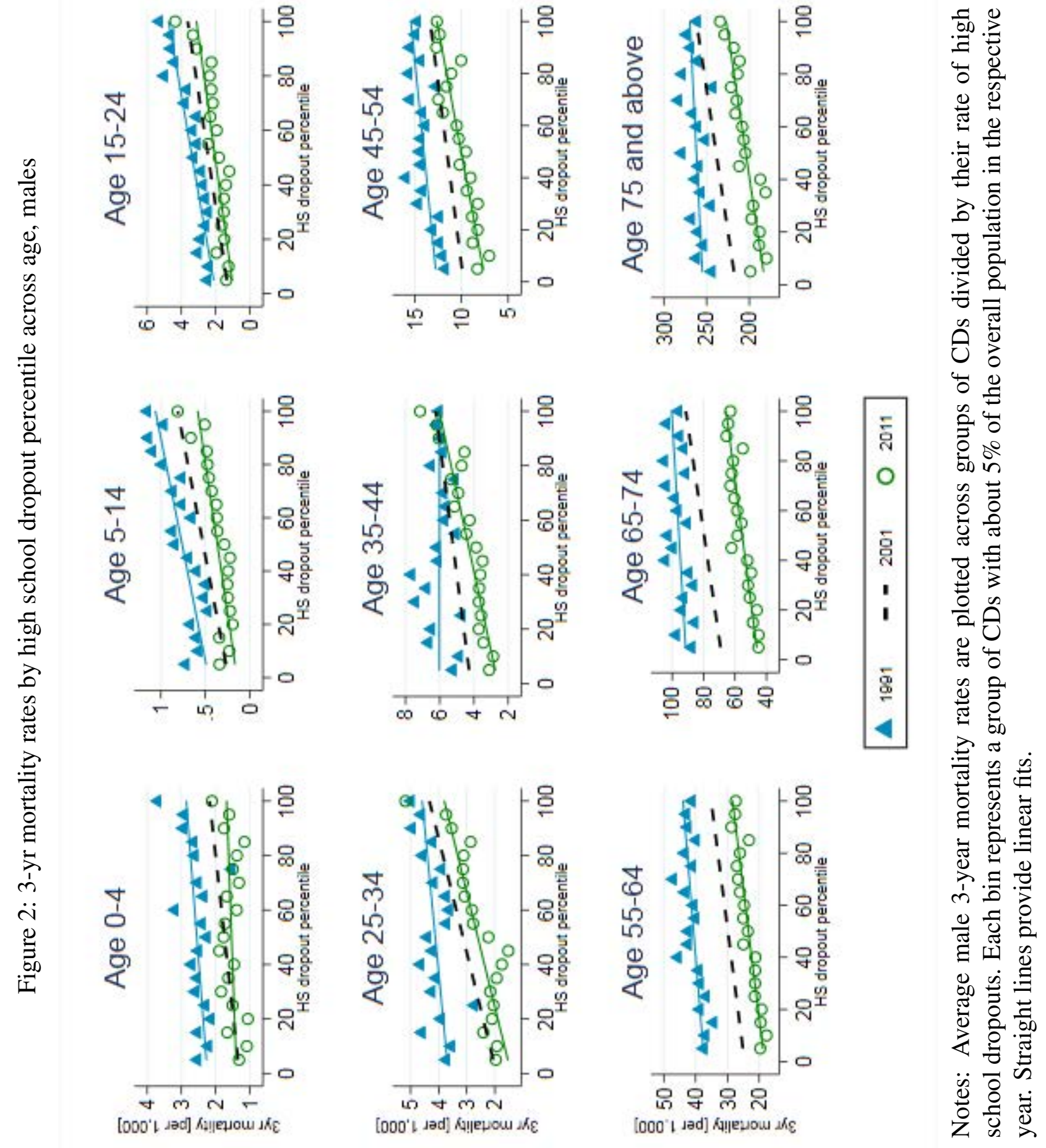




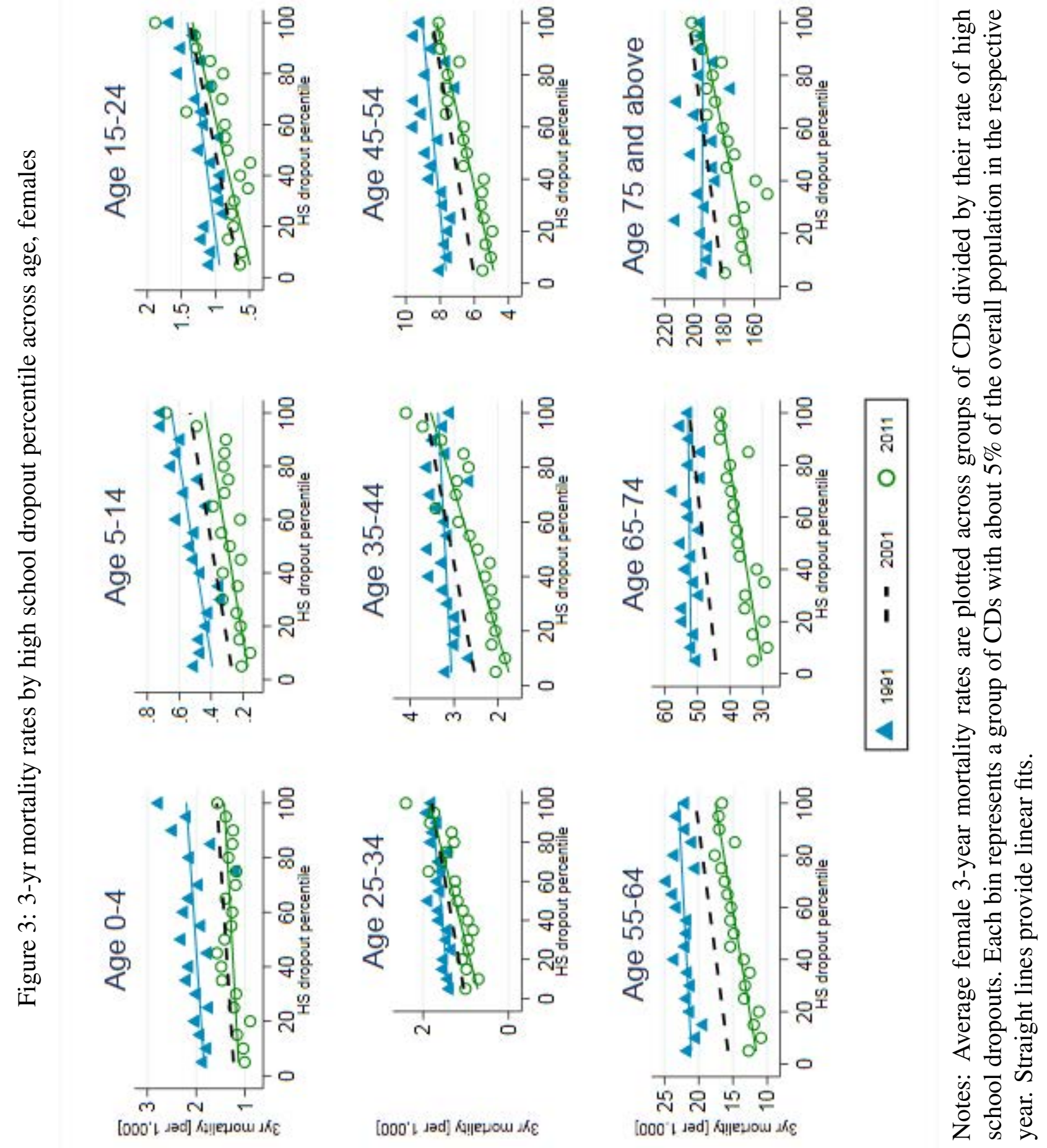




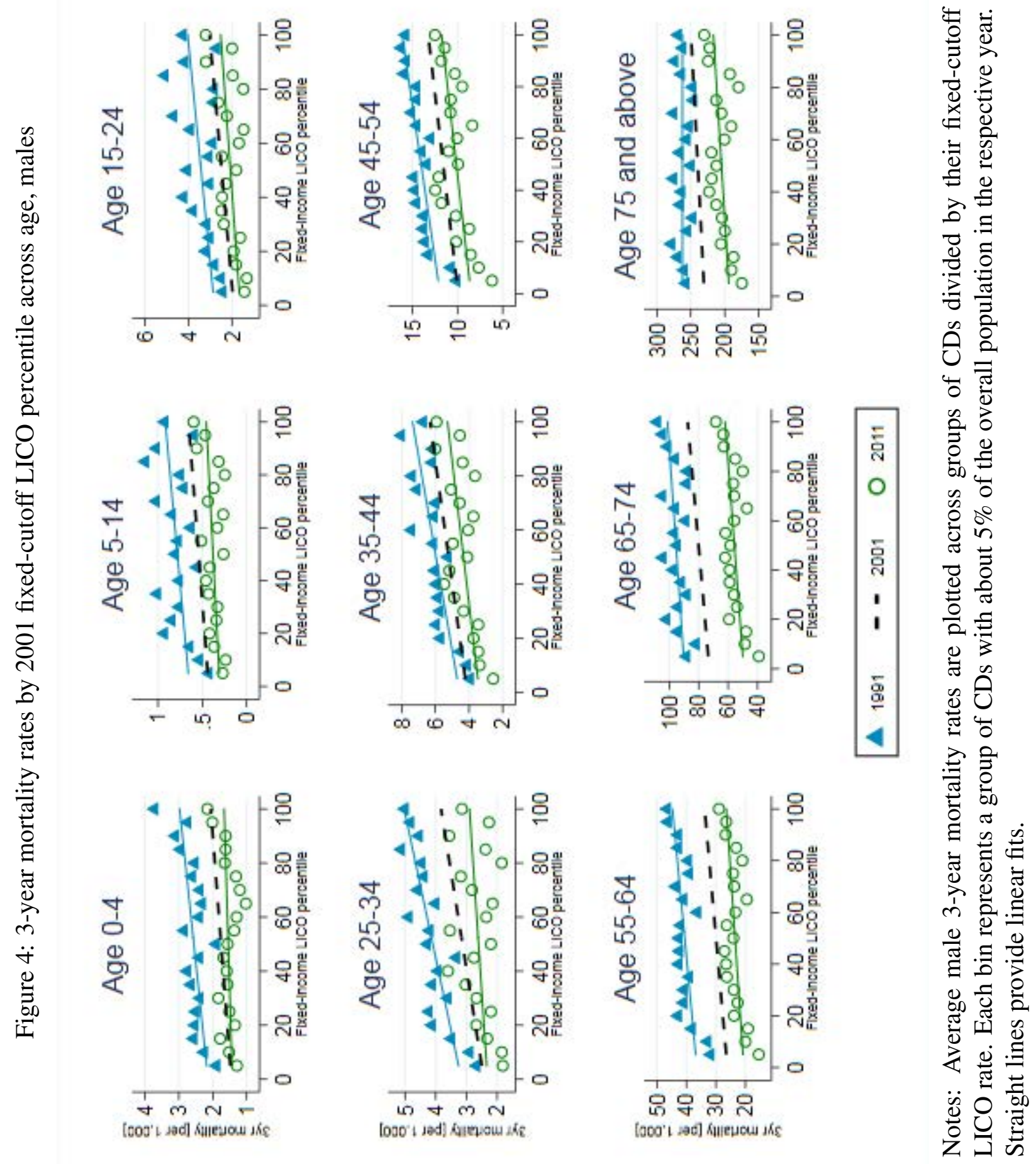




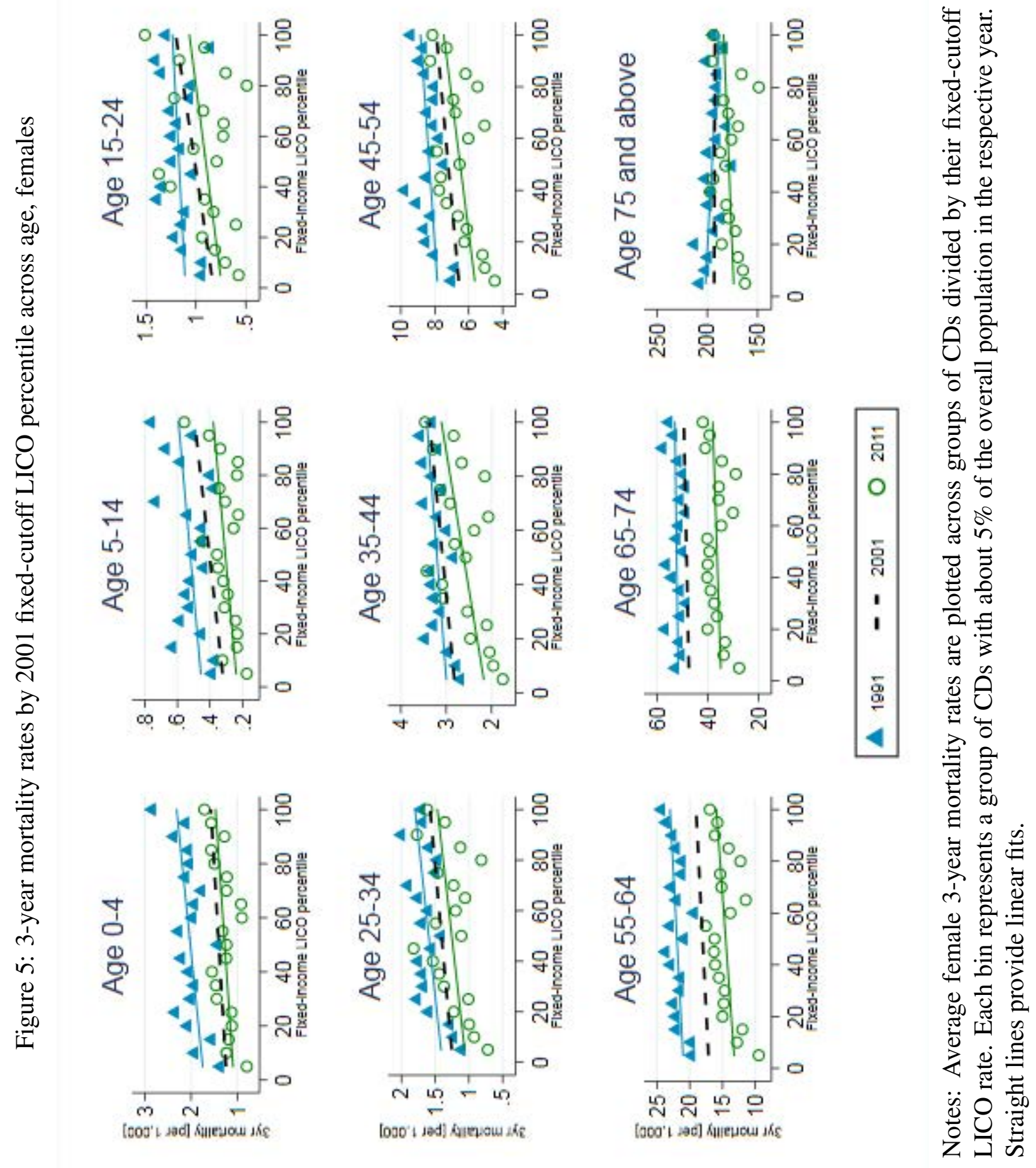




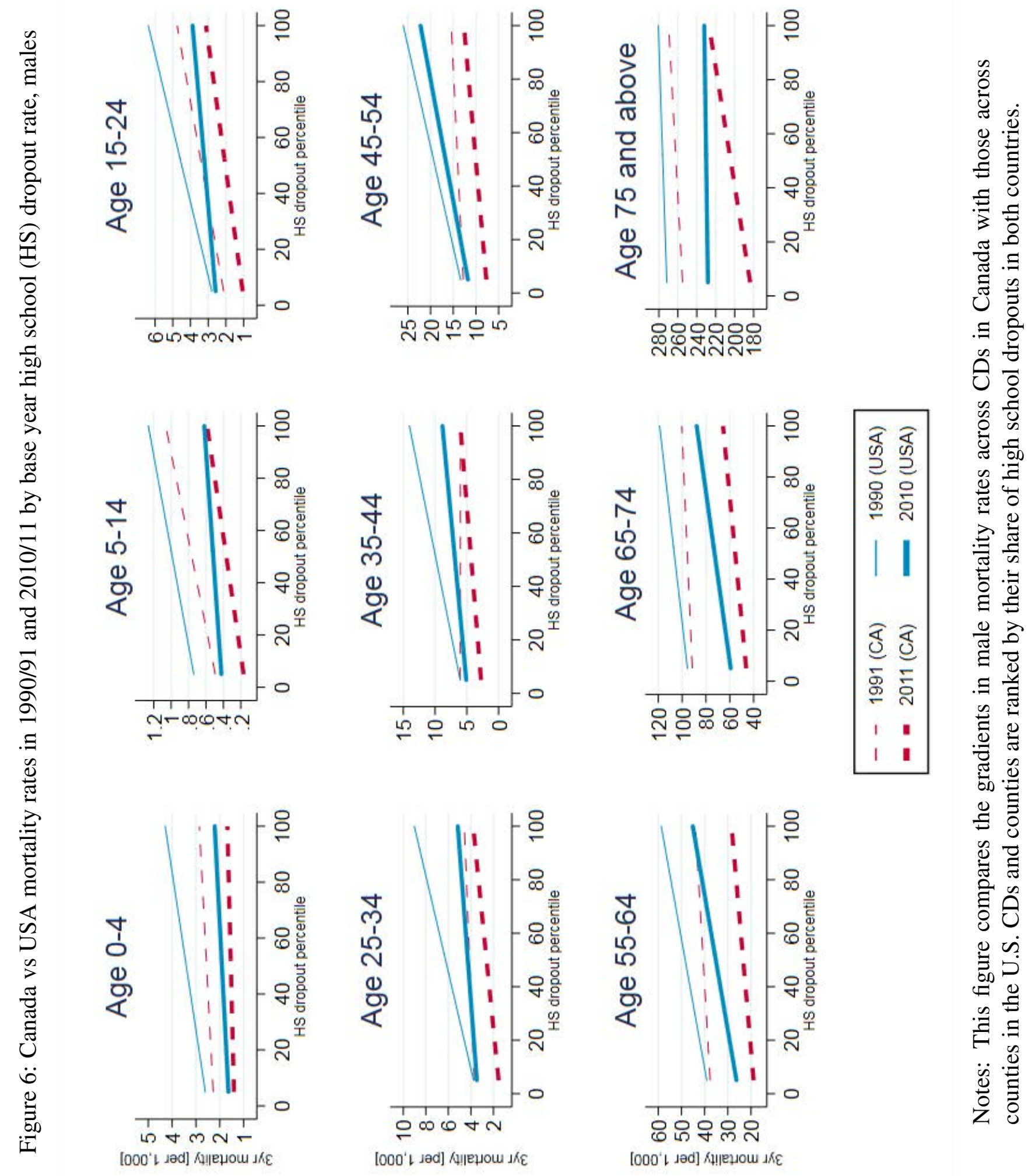




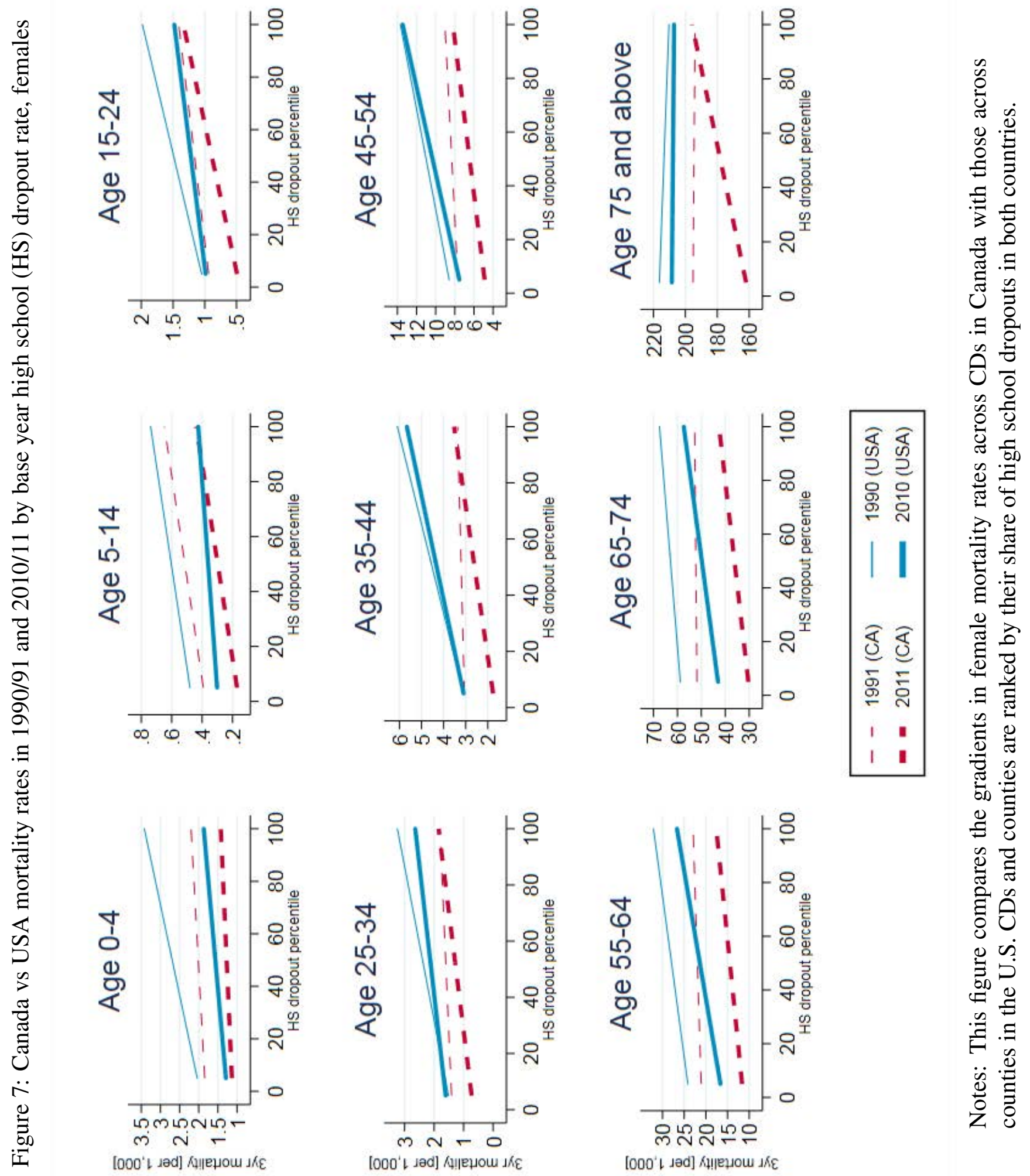




\section{Appendix}

\section{A Discussion of LICO poverty measures}

The analysis in the paper uses a "fixed-cutoff LICO", which varies by family size but not geography, to be consistent with US poverty lines and so facilitate the cross country comparison. However, it is more common in studies of poverty in Canada to simply use the LICO cutoffs as published by Statistics Canada. These cutoffs vary by family size and geographically by the size of the city/area of residence. This geographic variation is in the same spirit as the US Supplemental Poverty Measure cutoffs that vary geographically to account for differences in housing costs.

In Figures A.5 and A.4 we present morality profiles analogous to those in Figure 4 and 5, using the standard LICO cutoffs rather than the fixed cutoffs. The main change in inference relative to the fixed-cutoff LICO, which is most evident for the younger age groups and the 2011 data, is that the slope of the profiles is attenuated to the point that in some cases they are negatively sloped. This means that individuals located in areas of higher poverty have lower mortality rates, a counterintuitive result. The census divisions of Montreal, Toronto and Vancouver play a significant role in this reversal. They are CDs of both relatively high poverty according to the LICO measure and relatively low mortality.

Figures A.7 and A.6 show profiles recalculated using the standard LICO cutoffs but omitting these three CDs from the sample. The impact of this omission is that the problem of negatively sloped profiles (i.e. an apparently negative relationship between poverty and death rates) is mostly "solved". The slopes of the mortality profiles are positive just as they are when using the fixed-cutoff LICO. Using the fixed-cutoff LICO does not result in negative slopes because it "moves" these large CDs up the poverty percentile distribution. For example, moving from the standard to fixed-cutoff LICO, Toronto moves from the 18th ventile in 
each year to the 15th or 16th, and Vancouver moves from the 16th ventile in each year to the 11th or 12th. That is, Statistics Canada assumes that people need relatively high incomes to live a decent life in these large cities, which means that many people fall below the LICO cutoff in these areas even though the large cities seem to have attributes that contribute to relatiavely low mortality rates.

As one investigation of why Montreal, Toronto and Vancouver have this effect on the inference we have subdivided these CDs into smaller units to better match the size of the other CDs in the country. ${ }^{15}$ This division is only possible for the 1991 census year given constraints on the available data. The results (not shown) reveal that breaking these cities into smaller units both leads to more age groups exhibiting negative slopes, and an increase in the slope for age groups exhibiting negative sloped profiles in Figures A.5 and A.4. Intuitively, if the negative slopes result from the high LICO cutoffs chosen by statistics Canada in large cities, then increasing the number of observations with these high cutoffs by subdividing the large cities will exacerbate the problem.

Another possible reason for the large impact of these cities on inference is the high number of immigrants that live in them. In 2001 immigrants made up $18 \%$ of the population of Montreal, $44 \%$ of the population of Toronto and $38 \%$ of the population of Vancouver. ${ }^{16}$ Many Canadian immigrants are selected by a point system ${ }^{17}$ that ensures that they have high levels of education, but they may experience periods of low income after they arrive in Canada. Moreover, just as it has in the U.S., this relationship between immigration status and income poverty has grown stronger over time (e.g. Baker and Benjamin (1994); Green and Worswick (2012)). At the same time there is evidence of a "healthy immigrant effect"-immigrants have lower rates of morbidity and mortality at least initially than native

\footnotetext{
${ }^{15} \mathrm{We}$ are able to subdivide Montreal into 29 areas, Vancouver into 24 areas and Toronto into 6 areas.

${ }^{16} \mathrm{See} \quad \mathrm{https} / / / \mathrm{www} 12$. statcan.gc.ca/census-recensement/2016/as-sa/fogs-spg/select-GeoChoix.cfm?Lang=Eng\&GK=CMA\&TOPIC=7 accessed August 27, 2018.

${ }^{17}$ Since 2001 the proportion of immigrants admitted under the point system has averaged in excess of $55 \%$. See Bohnert et al. (2015) Chapter 5.
} 
born Canadians (e.g. McDonald and Kennedy (2004); Ng (2011)). Unfortunately there is no foreign birth indicator in the Canadian vital statistics that would allow us to explore this hypothesis.

Still another reason why large cities seem to have both larger shares of people below the LICO, and lower mortality is that there may be advantages to living in larger cities that offset some of the disadvantages of LICO identified low money income. These advantages could include better access to a family physicians and/or municipality supplied preventative and remedial health programs, as well as amenities such as public transportation and recreational opportunities. For example, there is evidence that there is much better access to family medical care in the Greater Toronto Area than in the rest of the province of Ontario (Bohnert et al., 2015). The LICO cutoffs are set primarily with regard to the costs of food and shelter. Under the fixed-cutoff LICO a lower proportion of the residents of these three cities are considered to be in poverty. Those who are placed above the poverty line when we adopt the fixed-cutoff LICO may be spending more on food and shelter than their in smaller CDs, but these higher costs may be largely offset by other health enhancing large-city amenities. Again is not possible to directly test this hypothesis with the data we have at hand. 


\section{B Appendix Figures}

Figure A.1: Canadian CDs ranked by HS dropout rate vs. LICO and fixed-cutoff LICO, in 2001

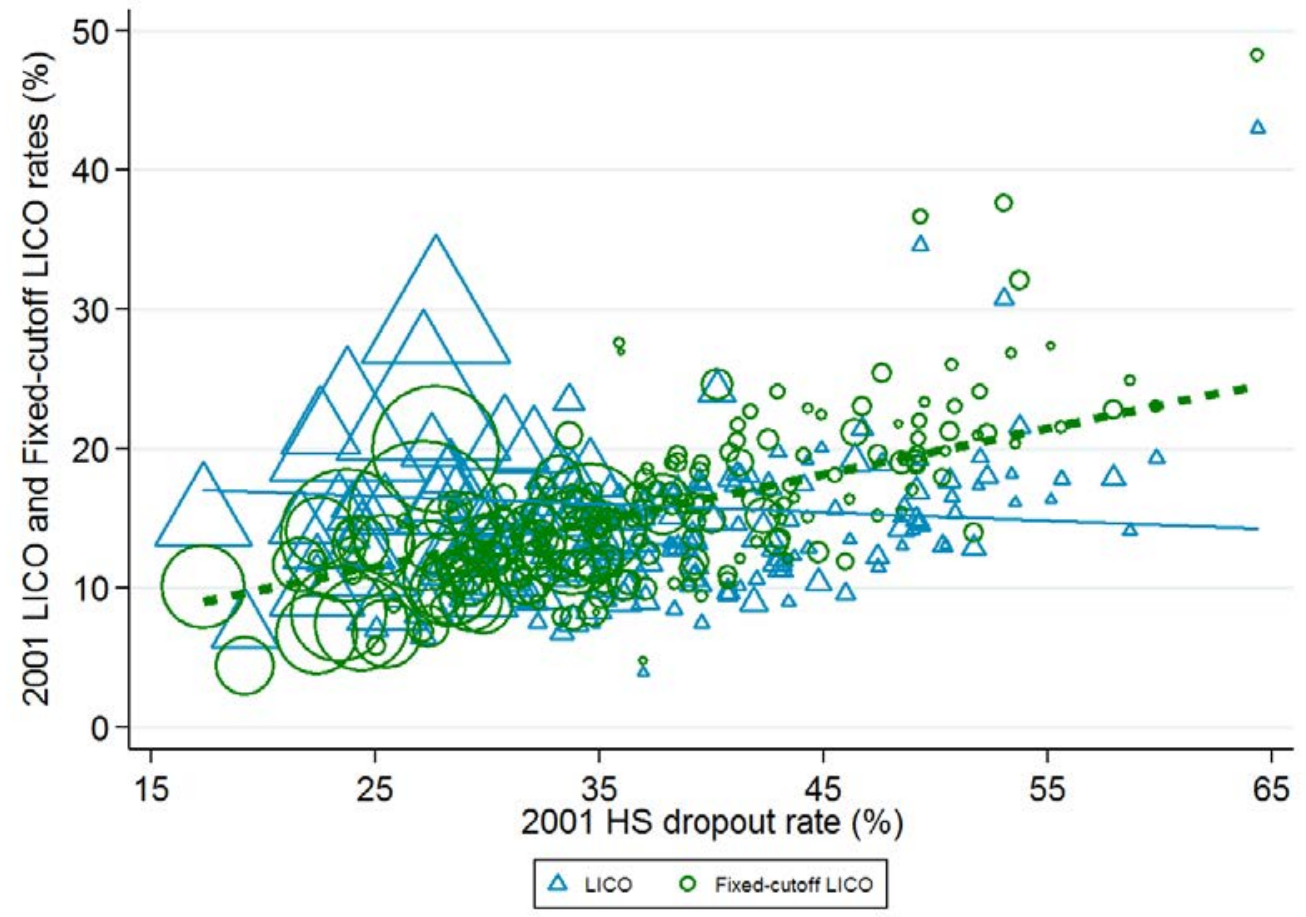

Notes: This figure compares high school dropout rates of individual CDs in 2011 with their LICO and fixed-cutoff LICO rates in the same year. Each marker represents one $\mathrm{CD}$ and the marker size is proportional to its population. 
Figure A.2: Canadian CDs ranked by high school drop out rate in 2001, vs. 1991 and 2011

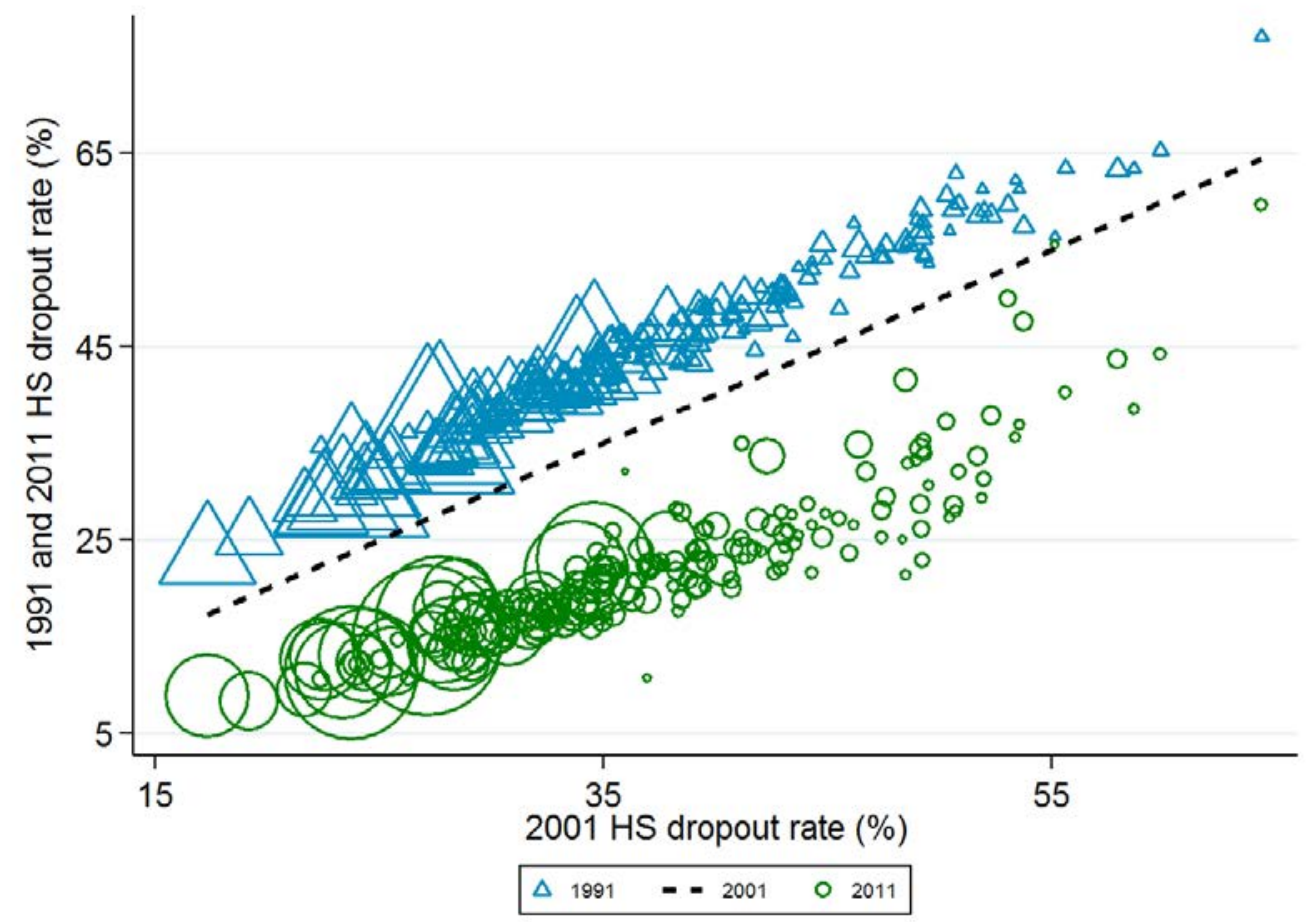

Notes: This figure compares high school dropout rates of individual CDs in 1991 and 2011 to their rate in 2001. Each marker represents one CD and the marker size is proportional to its population. 
Figure A.3: Canadian CDs ranked by fixed-cutoff LICO in 2001, vs. 1991 and 2011.

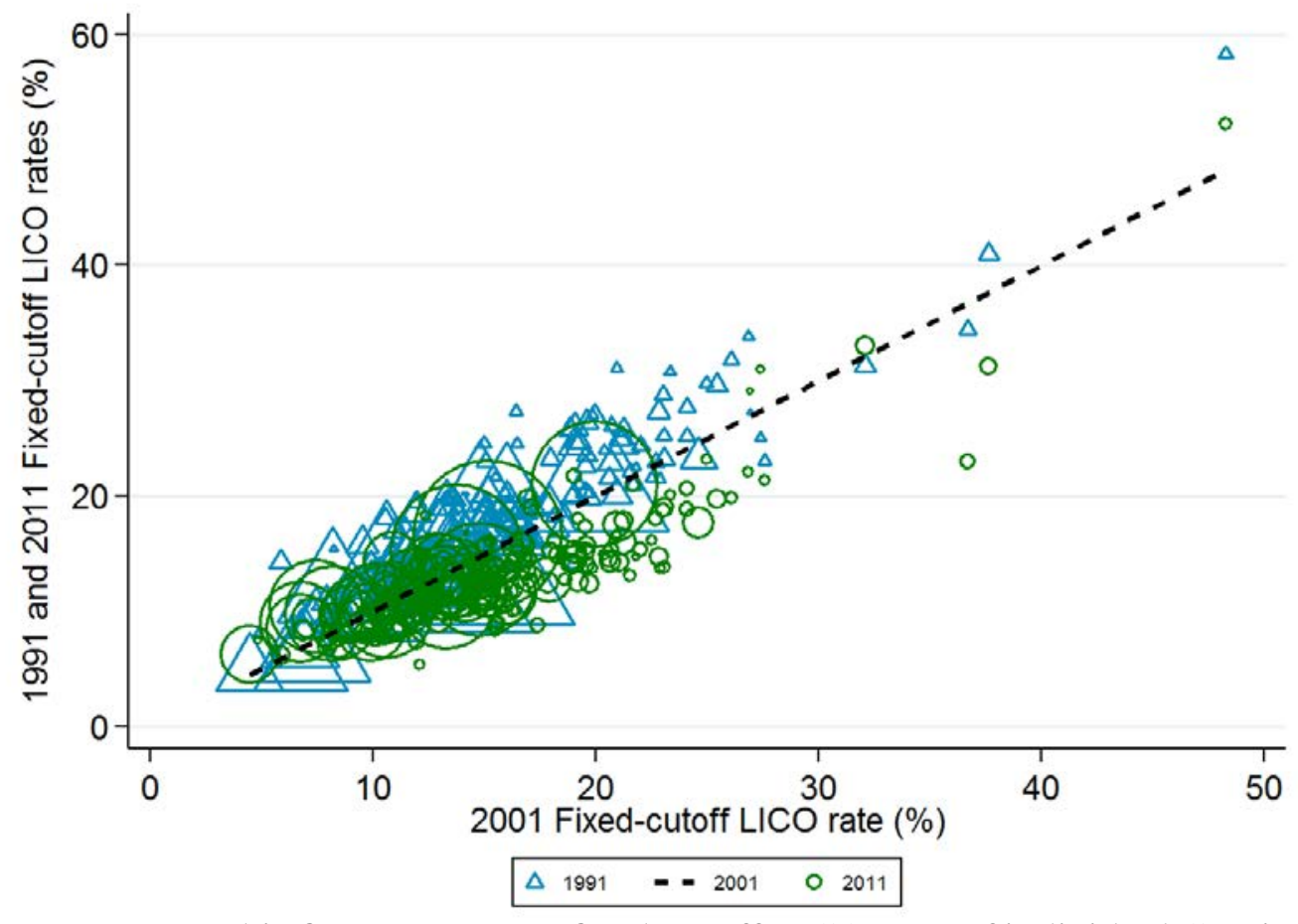

Notes: This figure compares fixed-cutoff LICO rates of individual CDs in 1991 and 2011 to their rate in 2001. Each marker represents one CD and the marker size is proportional to its population. 
Figure A.4: Male Mortality Profiles by Age using poverty ranking by Standard LICO
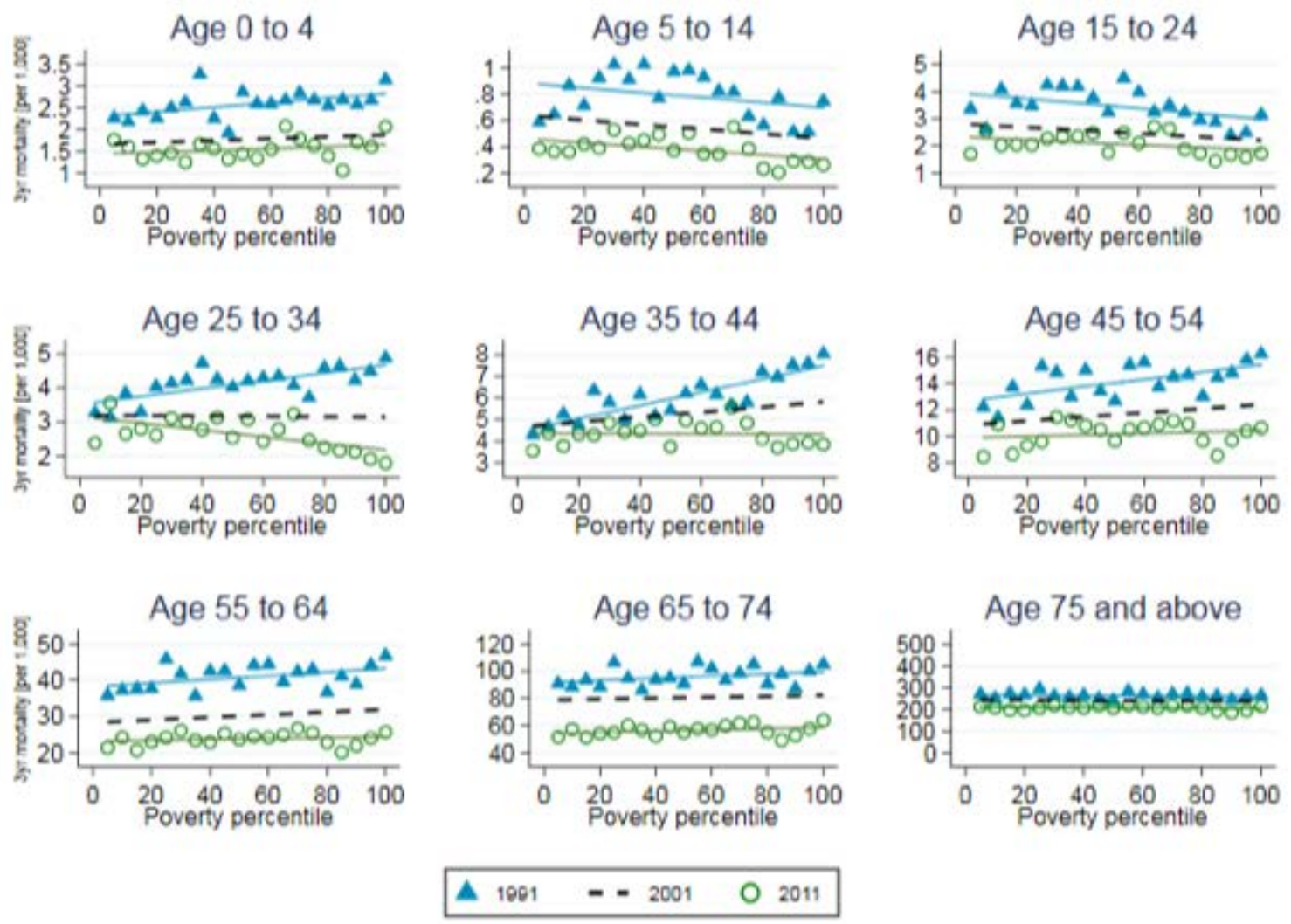

Notes: Average male 3-year mortality rates are plotted across groups of CDs divided by their LICO rate. Each bin represents a group of CDs with about 5\% of the overall population in the respective year. Straight lines provide linear fits. 
Figure A.5: Female Mortality Profiles by Age using poverty ranking by Standard LICO
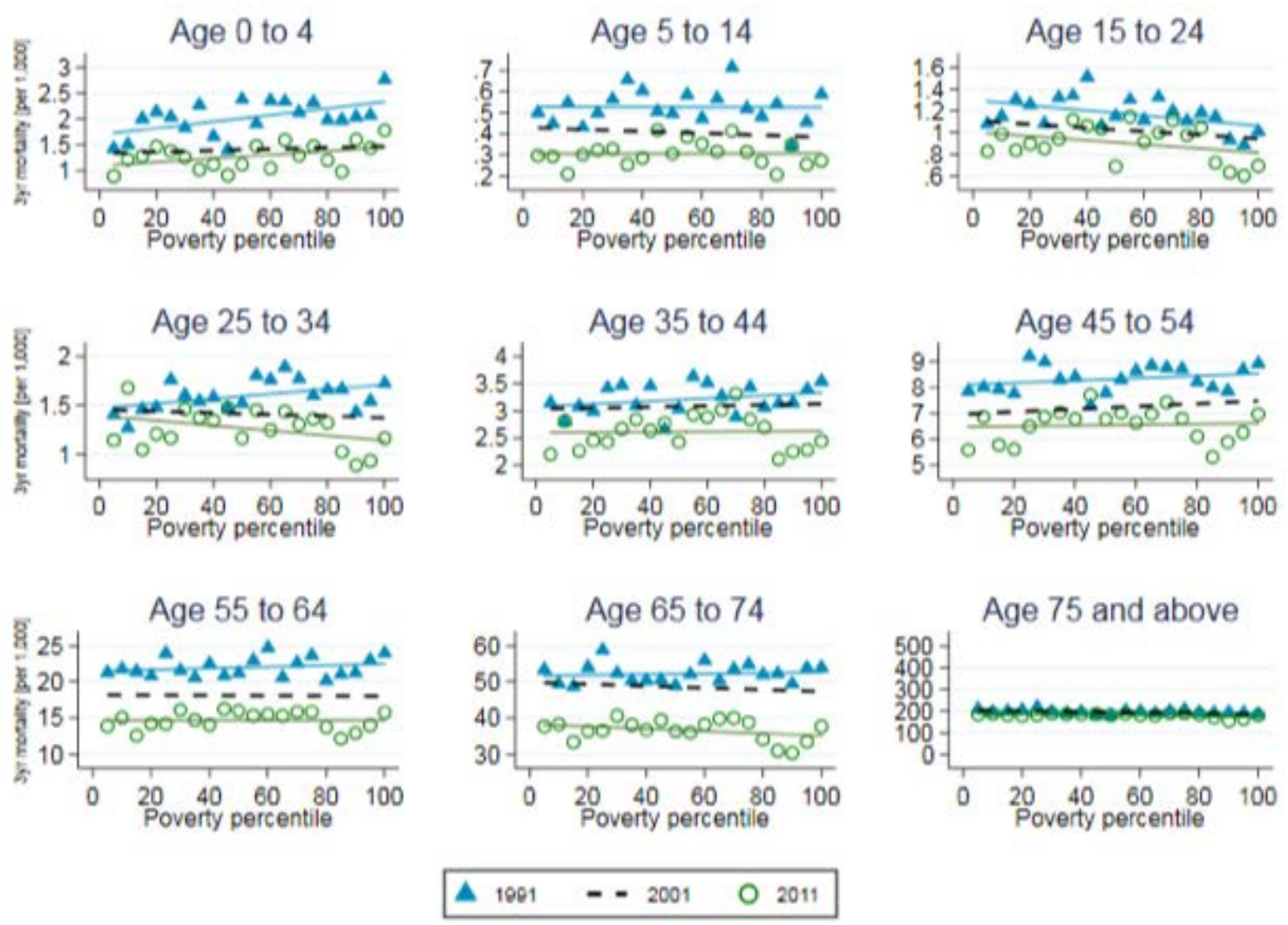

Notes: Average female 3-year mortality rates are plotted across groups of CDs divided by their LICO rate. Each bin represents a group of CDs with about $5 \%$ of the overall population in the respective year. Straight lines provide linear fits. 
Figure A.6: Male Mortality Profiles by Age using poverty ranking by Standard LICO, excluding Montreal, Toronto and Vancouver
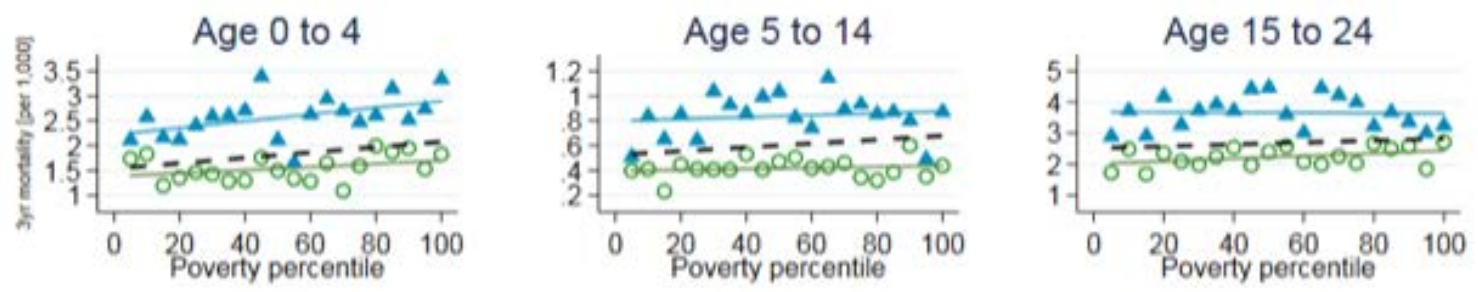

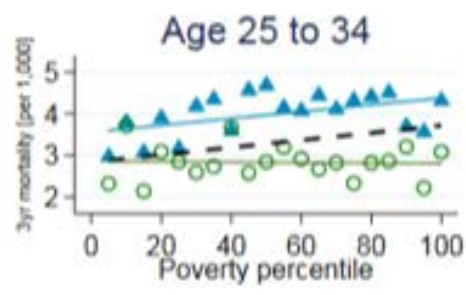

Age 35 to 44

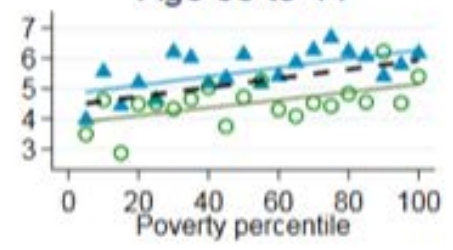

Age 55 to 64

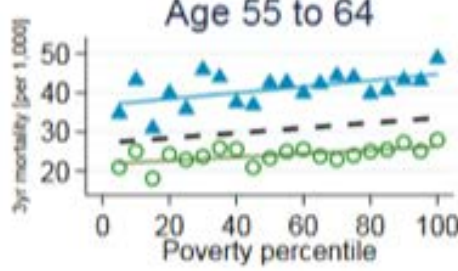

Age 65 to 74

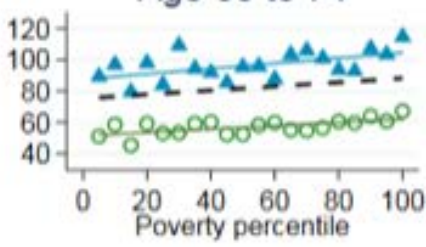

A 1991

O 2011
Age 45 to 54

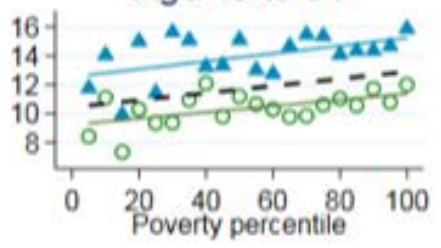

Age 75 and above

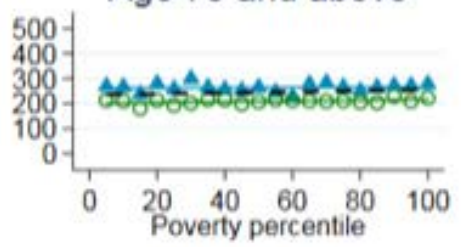

Notes: Average male 3-year mortality rates are plotted across groups of CDs divided by their LICO rate, excluding the cnesus divisions of Montreal, Toronto and Vancouver. Straight lines provide linear fits. 
Figure A.7: Female Mortality Profiles by Age using poverty ranking by Standard LICO, excluding Montreal, Toronto and Vancouver
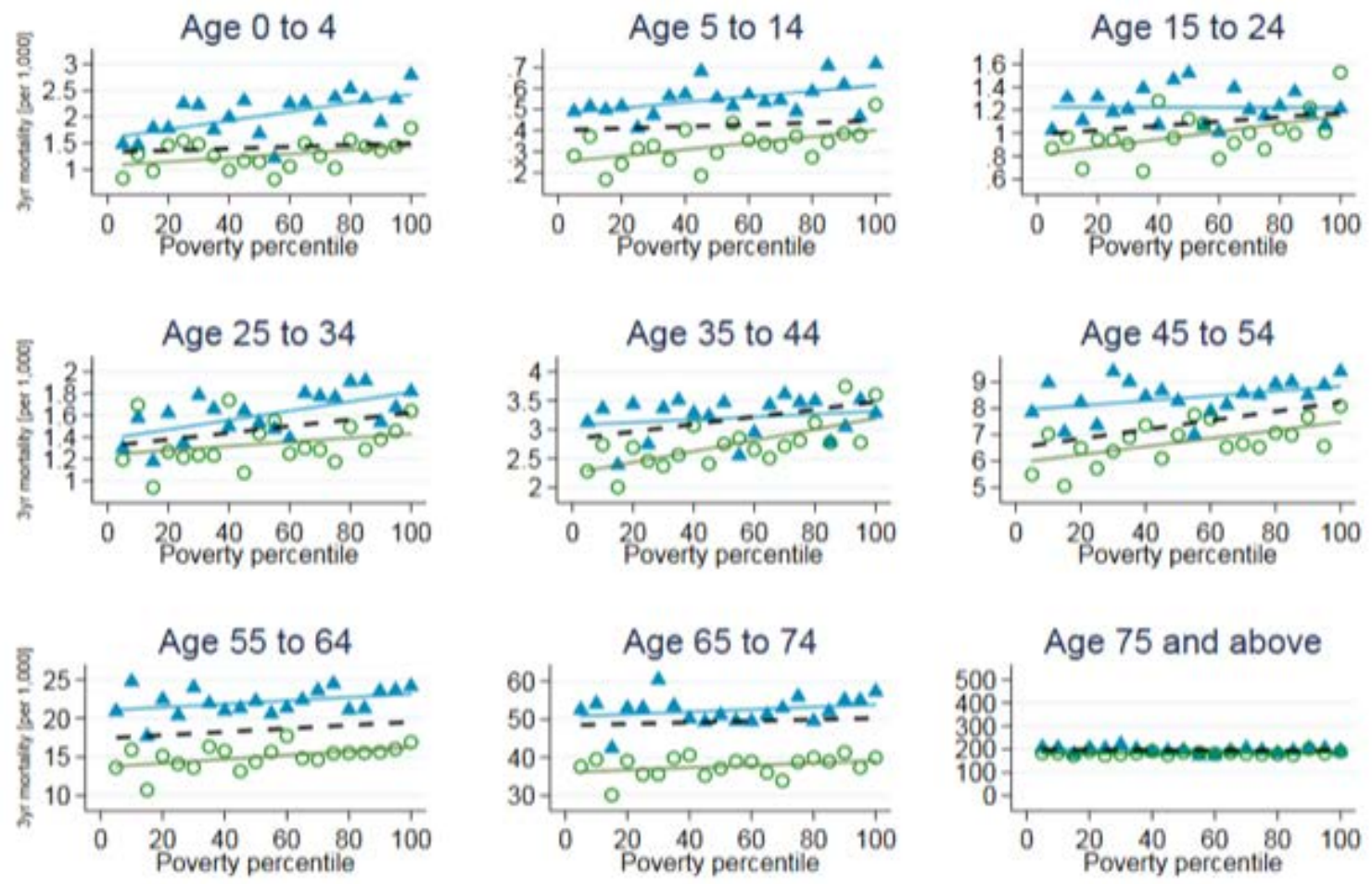

$$
\text { A } 1991 \quad \text { - } 2001 \quad \text { O } 2011
$$

Notes: Notes: Average female 3-year mortality rates are plotted across groups of CDs divided by their LICO rate, excluding the cnesus divisions of Montreal, Toronto and Vancouver. Straight lines provide linear fits. 
Figure A.8: Canada vs USA mortality rates in 1990/91 and 2010/11 by base year fixed-cutoff $\mathrm{LICO/poverty,} \mathrm{males}$
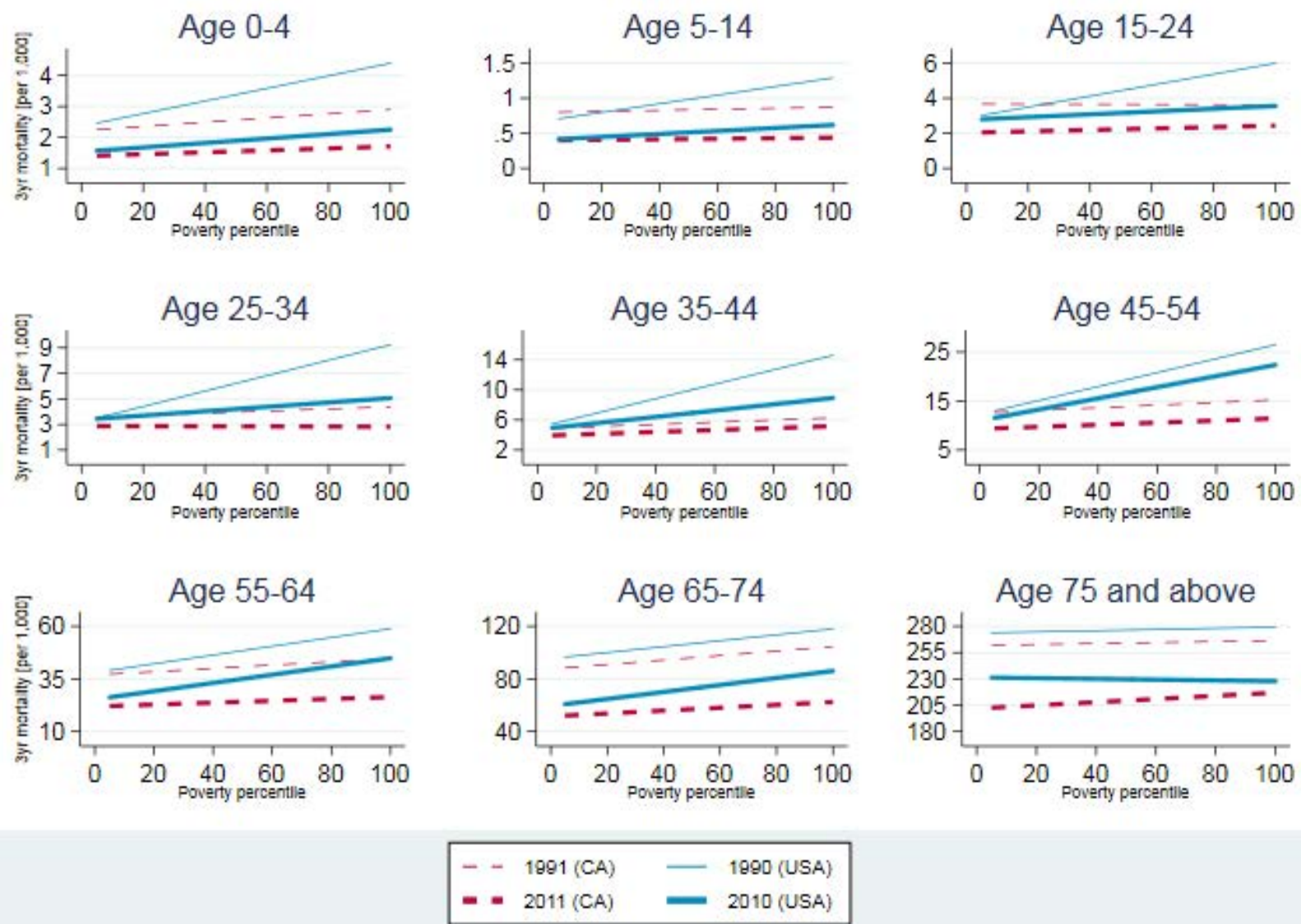

Notes: This figure compares the gradients in male mortality rates across CDs in Canada with those across counties in the U.S. CDs and counties are ranked by fixed-cutoff LICO rate in Canada and by their poverty rate in the U.S., respectively. 
Figure A.9: Canada vs USA mortality rates in 1990/91 and 2010/11 by base year fixed-cutoff LICO/poverty, females

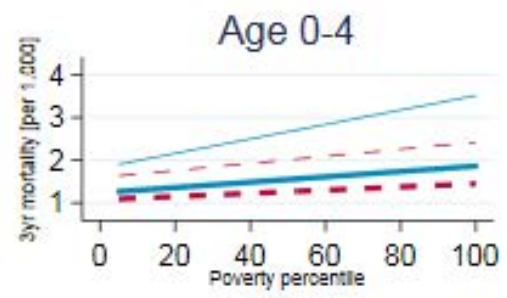

Age 5-14

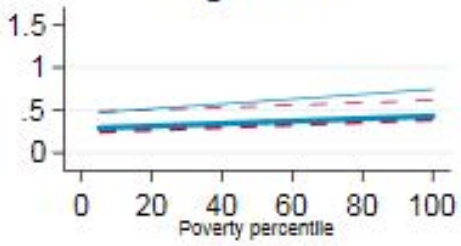

Age 15-24
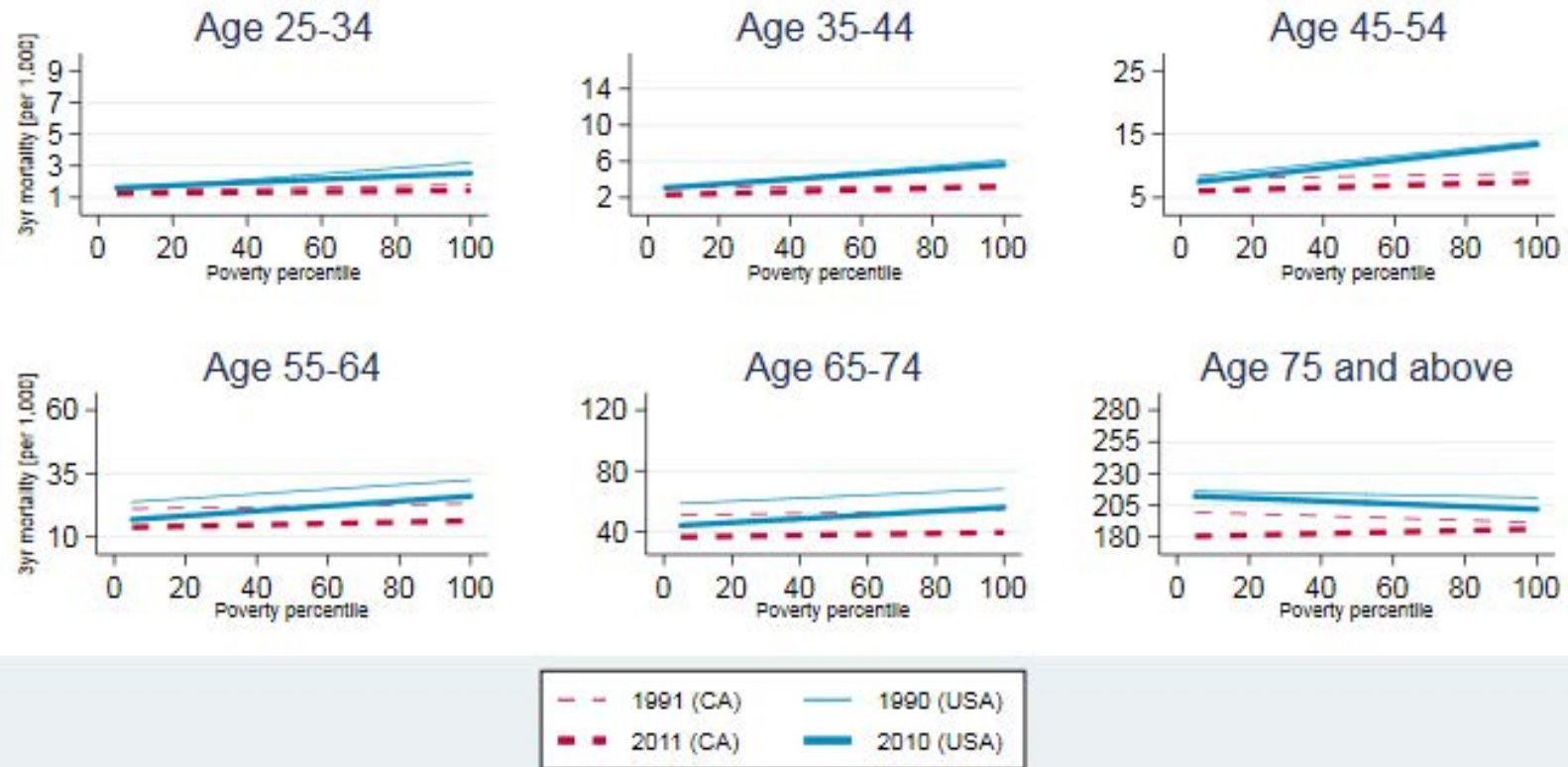

Notes: This figure compares the gradients in female mortality rates across CDs in Canada with those across counties in the U.S. CDs and counties are ranked by fixed-cutoff LICO rate in Canada and by their poverty rate in the U.S., respectively. 
Table A.1: Mortality rates by cause in Canada and the U.S., age 0 to 49

\begin{tabular}{|c|c|c|c|c|c|c|c|c|}
\hline & \multicolumn{4}{|c|}{2011 deaths per 100,000} & \multicolumn{4}{|c|}{ Change, 1991-2011 } \\
\hline & \multicolumn{2}{|c|}{ Canada } & \multicolumn{2}{|c|}{ U.S. } & \multicolumn{2}{|c|}{ Canada } & \multicolumn{2}{|c|}{ U.S. } \\
\hline & Male & Female & Male & Female & Male & Female & Male & Female \\
\hline & & & (A) $\mathrm{A}$ & & & & & \\
\hline All Causes & 537.7 & 439.0 & 658.4 & 552.4 & $-22 \%$ & $-25 \%$ & $-34 \%$ & $-30 \%$ \\
\hline Congenital anomalies & 112.6 & 100.0 & 129.9 & 123.5 & $-45 \%$ & $-47 \%$ & $-35 \%$ & $-29 \%$ \\
\hline $\begin{array}{l}\text { Short gestation/low } \\
\text { birth weight }\end{array}$ & 82.1 & 62.5 & 112.3 & 95.0 & $80 \%$ & $39 \%$ & $4 \%$ & $2 \%$ \\
\hline $\begin{array}{l}\text { Pregnancy } \\
\text { complications }\end{array}$ & 46.5 & 46.7 & 44.7 & 35.6 & $65 \%$ & $83 \%$ & $12 \%$ & $3 \%$ \\
\hline $\begin{array}{l}\text { Placenta, cord, } \\
\text { membranes problems }\end{array}$ & 36.7 & 22.8 & 27.1 & 23.6 & $52 \%$ & $-16 \%$ & $3 \%$ & $15 \%$ \\
\hline Sudden infant death & 21.2 & 16.8 & 54.7 & 41.6 & $-80 \%$ & $-76 \%$ & $-65 \%$ & $-59 \%$ \\
\hline Undetermined & 31.0 & 18.5 & 31.9 & 23.7 & $42 \%$ & $-14 \%$ & $30 \%$ & $18 \%$ \\
\hline
\end{tabular}

(B) Age 1-19

\begin{tabular}{lcccccccc} 
All Causes & 24.3 & 15.3 & 32.7 & 18.3 & $-47 \%$ & $-38 \%$ & $-44 \%$ & $-41 \%$ \\
\hline Accidents & 8.9 & 3.3 & 12.2 & 5.4 & $-59 \%$ & $-55 \%$ & $-52 \%$ & $-50 \%$ \\
Accidental Drug & & & & & & & & \\
Poisoning & 0.4 & 1.3 & 0.5 & $385 \%$ & $50 \%$ & $440 \%$ & $301 \%$ \\
Cancer & 2.7 & 2.0 & 2.6 & 2.1 & $-33 \%$ & $-33 \%$ & $-34 \%$ & $-30 \%$ \\
Suicide & 4.0 & 2.1 & 4.1 & 1.2 & $-38 \%$ & $65 \%$ & $-17 \%$ & $5 \%$ \\
Assault & 1.2 & 0.7 & 4.6 & 1.3 & $34 \%$ & $-51 \%$ & $-52 \%$ & $-48 \%$ \\
\hline Undetermined & 1.0 & 0.3 & 0.8 & 0.6 & $-48 \%$ & $-74 \%$ & $-35 \%$ & $-31 \%$
\end{tabular}

(C) Age 20-34

\begin{tabular}{lcccccccc} 
All Causes & 75.7 & 35.7 & 137.2 & 58.4 & $-42 \%$ & $-25 \%$ & $-28 \%$ & $-14 \%$ \\
\hline Accidents & 28.1 & 8.3 & 54.3 & 19.0 & $-45 \%$ & $-34 \%$ & $-1 \%$ & $17 \%$ \\
Accidental Drug & 7.4 & 2.8 & 21.7 & 8.7 & $58 \%$ & $147 \%$ & $351 \%$ & $570 \%$ \\
Poisoning & & & & & & & & \\
Suicide & 18.4 & 6.2 & 22.8 & 5.5 & $-40 \%$ & $-4 \%$ & $-9 \%$ & $11 \%$ \\
Cancer & 6.0 & 6.1 & 7.1 & 6.9 & $-38 \%$ & $-40 \%$ & $-31 \%$ & $-32 \%$ \\
Assault & 4.3 & 1.4 & 18.6 & 3.4 & $-12 \%$ & $-39 \%$ & $-44 \%$ & $-56 \%$ \\
\hline Undetermined & 2.5 & 1.5 & 2.5 & 1.4 & $-57 \%$ & $-40 \%$ & $-46 \%$ & $-28 \%$
\end{tabular}

Notes: For comments see notes under the next table 
Table A.2: Mortality rates by cause in Canada and the U.S., age 50 and above

\begin{tabular}{|c|c|c|c|c|c|c|c|c|}
\hline & \multicolumn{4}{|c|}{2011 deaths per 100,000} & \multicolumn{4}{|c|}{ Change, 1991-2011 } \\
\hline & \multicolumn{2}{|c|}{ Canada } & \multicolumn{2}{|c|}{ U.S. } & \multicolumn{2}{|c|}{ Canada } & \multicolumn{2}{|c|}{ U.S. } \\
\hline & Male & Female & Male & Female & Male & Female & Male & Female \\
\hline \multicolumn{9}{|c|}{ (D) Age 35-49 } \\
\hline All Causes & 164.0 & 105.3 & 278.2 & 173.5 & $-31 \%$ & $-20 \%$ & $-23 \%$ & $0 \%$ \\
\hline Accidents & 28.6 & 10.1 & 55.4 & 25.5 & $-24 \%$ & $-19 \%$ & $22 \%$ & $80 \%$ \\
\hline $\begin{array}{l}\text { Accidental Drug } \\
\text { Poisoning }\end{array}$ & 10.4 & 5.0 & 23.8 & 15.2 & $176 \%$ & $123 \%$ & $282 \%$ & $697 \%$ \\
\hline Cancer & 35.6 & 45.5 & 41.2 & 49.1 & $-32 \%$ & $-31 \%$ & $-29 \%$ & $-25 \%$ \\
\hline Heart Diseases & 24.9 & 8.0 & 54.5 & 22.7 & $-42 \%$ & $-22 \%$ & $-23 \%$ & $-1 \%$ \\
\hline Suicide & 22.5 & 7.5 & 26.5 & 8.3 & $-17 \%$ & $-4 \%$ & $14 \%$ & $20 \%$ \\
\hline Undetermined & 4.4 & 2.2 & 3.8 & 2.5 & $-52 \%$ & $-43 \%$ & $-47 \%$ & $-20 \%$ \\
\hline
\end{tabular}

(E) Age 50-64

\begin{tabular}{lcccccccc} 
All Causes & 611.2 & 388.1 & 900.0 & 545.1 & $-40 \%$ & $-31 \%$ & $-27 \%$ & $-24 \%$ \\
\hline Cancer & 239.7 & 213.8 & 268.7 & 210.8 & $-40 \%$ & $-28 \%$ & $-35 \%$ & $-33 \%$ \\
Heart Diseases & 127.2 & 111.8 & 219.1 & 141.1 & $-59 \%$ & $-38 \%$ & $-47 \%$ & $-37 \%$ \\
Accidents & 32.7 & 12.7 & 59.6 & 26.4 & $-22 \%$ & $-24 \%$ & $36 \%$ & $57 \%$ \\
Accidental Drug & 6.6 & 4.3 & 18.2 & 12.1 & $220 \%$ & $175 \%$ & $1071 \%$ & $1066 \%$ \\
Poisoning & & & & & & & & \\
Suicide & 23.4 & 8.5 & 28.7 & 8.5 & $-8 \%$ & $30 \%$ & $15 \%$ & $28 \%$ \\
\hline Undetermined & 7.3 & 3.9 & 8.2 & 4.8 & $-60 \%$ & $-46 \%$ & $-11 \%$ & $0 \%$
\end{tabular}

(F) Age 65 and above

\begin{tabular}{|c|c|c|c|c|c|c|c|c|}
\hline All Causes & 2965.4 & 2078.1 & 3408.0 & 2521.0 & $-36 \%$ & $-24 \%$ & $-29 \%$ & $-18 \%$ \\
\hline Cancer & 1105.6 & 770.0 & 1013.3 & 705.5 & $-23 \%$ & $-5 \%$ & $-26 \%$ & $-13 \%$ \\
\hline Heart Diseases & 611.1 & 346.6 & 848.1 & 525.8 & $-59 \%$ & $-60 \%$ & $-52 \%$ & $-51 \%$ \\
\hline $\begin{array}{l}\text { Chronic Lower } \\
\text { Respiratory }\end{array}$ & 161.0 & 127.2 & 250.7 & 212.1 & $-47 \%$ & $17 \%$ & $-16 \%$ & $32 \%$ \\
\hline Cerebrovascular & 141.0 & 121.5 & 158.1 & 152.0 & $-53 \%$ & $-50 \%$ & $-44 \%$ & $-38 \%$ \\
\hline Undetermined & 21.2 & 14.1 & 29.6 & 28.3 & $-63 \%$ & $-60 \%$ & $12 \%$ & $60 \%$ \\
\hline
\end{tabular}

Notes: Death rates are calculated using a population-weighted average of five-year age group death rates, provided by Statistics Canada and the U.S. Centers for Disease Control. For each age group, causes of death displayed are Canada's four leading causes within that age group in 2011. Where accidents are a leading cause of death, accidental drug poisoning (a subset of accidents) is also displayed. The exception is 0-19 year-57ds, as accidental drug poisoning was not recorded in some years in that age group. 